Sheffield Hallam University
Centre for

Regional Economic and Social Research

\title{
Reaching the "Hardest to Reach' with energy advice: final report
}

\section{September 2019}
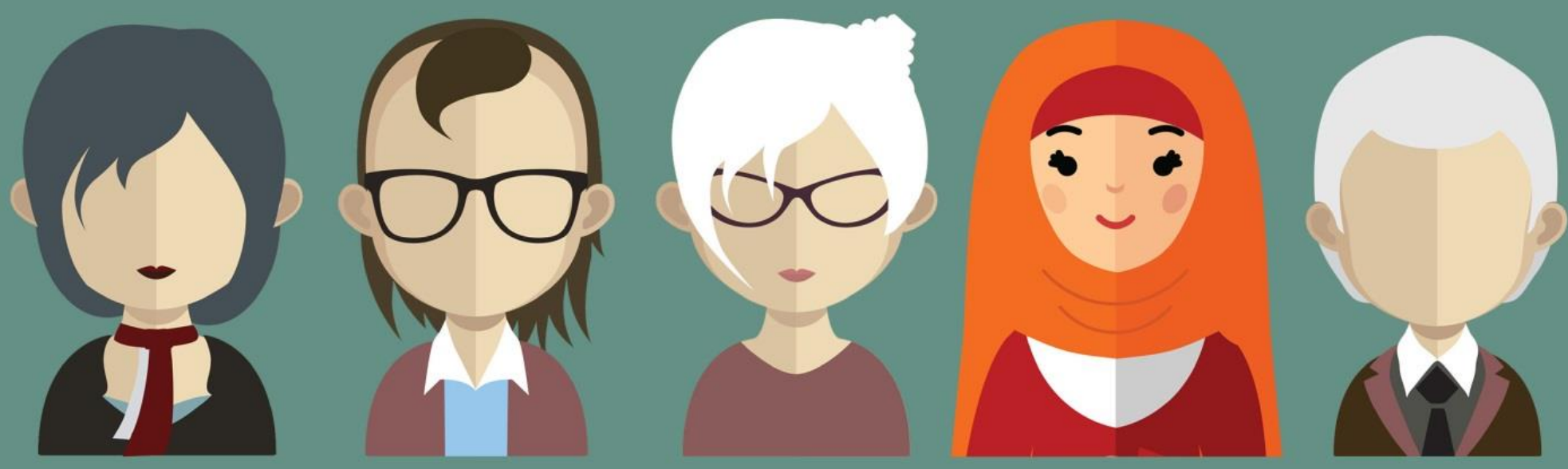


\section{Reaching the 'Hardest to Reach' with energy advice: final report}

Author(s):

Aimee Ambrose

William Baker (Citizens Advice)

Elaine Batty

Anna Hawkins

September 2019

DOI: 10.7190/cresr.2019.8286642862 


\section{Acknowledgements}

The project team are very grateful to many individuals and organisations for their invaluable support for this project. First and foremost we are indebted to those individuals who, despite their complex circumstances and often stressful daily lives, spared the time to participate in the citizens panel exercise and to recount difficult experiences to the team. We are hugely grateful for you time, your insights and your ideas about how experiences of energy advice could be improved.

We are also very grateful to all those who participated in our Stakeholder Reference Group. This provided a vital sounding board throughout the project and ensured that the project remained sensitive to policy and practice. Thank you for your enthusiasm and for your many excellent ideas about how experiences for hard to reach energy users can be improved. We are also very grateful to Dan Wostenholme and Remi Bec for their support and for facilitating a lively and productive final stakeholder workshop. We also acknowledge the vital financial support provided the Higher Education Innovation Fund (HEIF) and for the in-kind support provided to the project by Sheffield Hallam University and Citizens Advice. 


\section{The Authors}

Dr Aimee Ambrose is a Reader in Energy Policy at CRESR, Sheffield Hallam University where she has worked for the last ten years. Since June 2019 she has acted as Chief Academic Advisor to an international Technology Collaboration Programme (TCP) sponsored by the International Energy Agency which focuses on hard to reach energy users around the world. Her research is, amongst other things, concerned with the study of fuel poverty including raising awareness of lived experiences of the phenomenon and the efficacy and inclusivity of policies and initiatives intended to alleviate it. She has led numerous (national and local) evaluations of fuel poverty policy initiatives and has conducted detailed qualitative research into, inter alia, drivers of fuel poverty within the private rented sector- a pressing international policy concern. She has explored this issue (and published her research) in the UK, New Zealand and Australia. She is also a founding member and Chair of the Fuel Poverty Research Network- an international network that brings together the producers and users of fuel poverty research from across academia, policy and practice.

William Baker is the Energy Advice Development Lead at Citizens Advice. He is responsible for developing the capacity of the Citizens Advice service to provide energy advice to its clients, many of whom are on a low income and/or in vulnerable circumstances. Prior to Citizens Advice, William was head of fuel poverty policy at Consumer Focus, fuel poverty lead at the Centre for Sustainable Energy and the anti-poverty officer for several local authorities. William has either commissioned or led research on a wide range of fuel poverty topics including rural fuel poverty, small area fuel poverty indicator, local and area-based approaches to tackling fuel poverty, social tariffs and the impact of energy market liberalisation on low income consumers. William is a former chair of the End Fuel Poverty Coalition and remains closely involved in its work. He is currently a trustee of Eaga Charitable Trust and a member of the Fuel Poverty Research Network steering group.

Elaine Batty is a Research Fellow in CRESR, Sheffield Hallam University where she has worked for the last 20 years. Her research is mainly focussed on the lived experience of vulnerable people, such as homeless people, older people and those with complex circumstances such as drug and alcohol users and those experiencing mental health problems. She also has a keen interest in exploring and raising awareness of how people get by and manage on a day to day basis, especially in relation to fuel poverty.

Anna MacNair Hawkins is a Senior Lecturer at the Department of Natural and Built Environment at Sheffield Hallam University. Her research focuses on consumption practices and how they can evolve to meet the challenges of urbanisation, climate change and resource depletion whilst narrowing inequalities and improving quality of life. The themes she explores within this context include: domestic energy practices amongst marginalized communities, food charity responses to food poverty, healthy diet as a sustainable consumption practice, and how health is shaped by place. 


\section{Foreword}

The research presented in this report has important implications for energy policy development in the coming years.

First, the experiences of participants in this research add to the chorus of damning evidence of energy suppliers failing to provide basic empathy required to support consumers in vulnerable circumstances. In line with concerns from Citizens Advice and the recent Commission for Vulnerable Customers (CVC), the experiences narrated here show clear evidence for the need for firm enforcement of existing regulation by Ofgem and an industry commitment to putting their house in order. The CVC recommends a Code of Conduct for energy suppliers to be implemented to deliver the confidence that all consumers, whatever their circumstances, are supported. This report provides new evidence for the urgent need for the development and implementation of the CVC Code to ensure that no future consumer faces the appalling

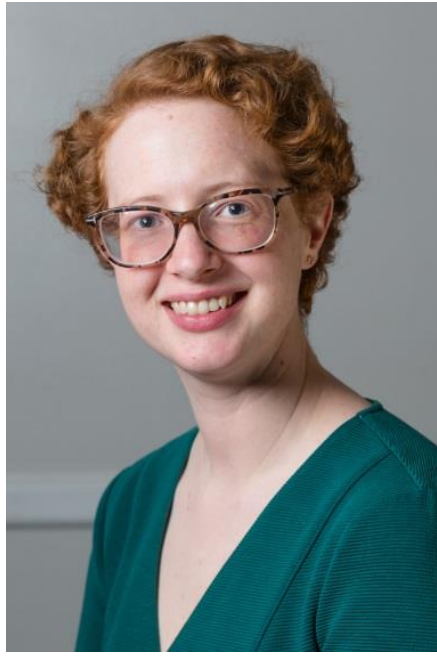
experiences of participants in this research.

Second, it provides further evidence that our approach to installing the energy efficiency measures that can transform people's health and wellbeing continue to fail to reach those most in need. This is a concern for all of those in Great Britain, particularly in England where the Energy Company Obligation provides the main access to energy efficiency measures to people in fuel poverty.

Finally, this report provides a blueprint for the absolute necessity of directly engaging with people to understand the consequences of our existing energy policies. People given the opportunity to consider the challenges and barriers have, as presented by this report, provided practical solutions. In ensuring these solutions consider all consumers, whatever their circumstances, this report does not begin with the tick-box definitions inherited by many existing approaches to identifying and then supporting consumers in vulnerable circumstances. Instead, you can read a nuanced understanding of energy advice and the people who have, in the past, been labelled 'hard to reach'.

Engaging directly with the nuance of overlapping challenges in accessing energy advice and the variation in advice needs identifies the need to consider more tailored approaches by firms providing access to energy - an essential-to-life service. Previous work has identified that innovation in the energy market has yet to benefit consumers in vulnerable circumstances (Sustainability First, 2018). Recent Citizens Advice research raises the concern that this is likely to continue under future energy market models without adopting specific commitments to inclusivity (Crisp \& Kruja, 2019). This research provides hope that this need not be the case. Tailored solutions that respond to consumer needs that make up the narrative of innovative products in the future. Tailored solutions and services that respond to specific needs are precisely the response needs identified in this report.

We face an unprecedented period of intense energy policy development in the coming years as we transform our society to respond to the challenges of climate change. This will mean a transformation in the way we use energy in our homes. As we undergo this policy change, there is significant risk that those who are most at risk of the impact of climate change, the most vulnerable in society, see their challenges in accessing affordable energy services exacerbated by a failure of policy makers to acknowledge the distribution of the costs of changing our energy system. This 
research will provides important insight into how we must go about engaging with this policy challenge - hearing the voices of to deliver authentic, practical solutions to benefit all consumers.

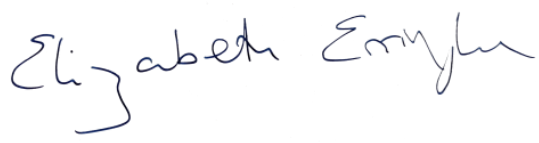

\section{Elizabeth Errington}

\section{Citizens Advice Energy Policy Team}




\section{Contents}

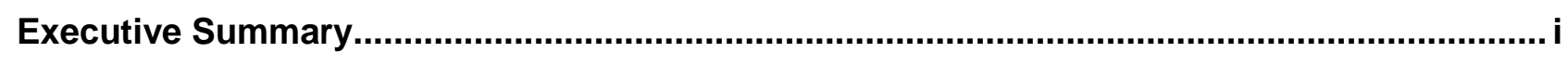

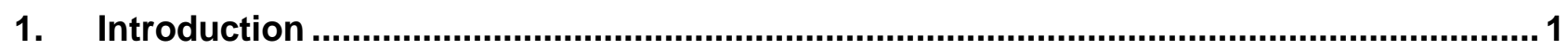

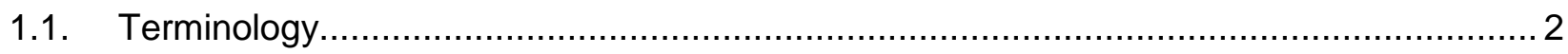

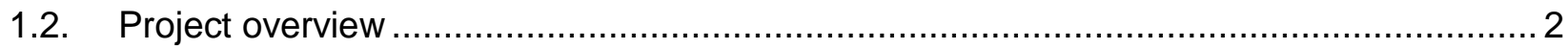

2. Providing energy advice to the hard to reach: a review of current thinking, policy and

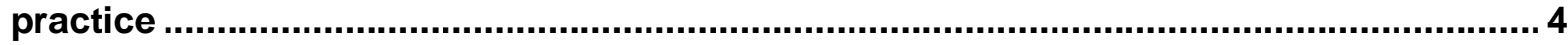

2.1. Who are the 'hard to reach'? …........................................................................... 4

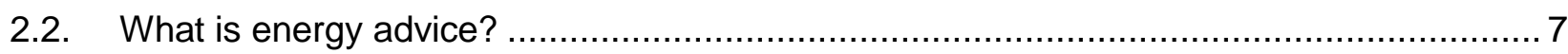

2.3. The essential nature of energy services ............................................................. 12

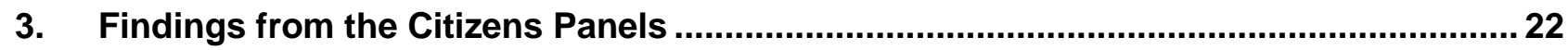

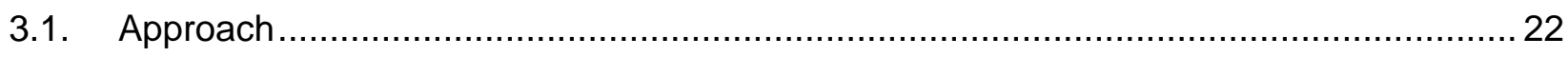

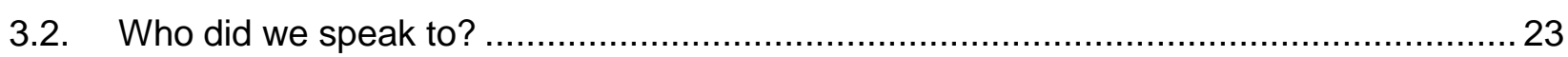

3.3. The nature of the energy related problems experienced ........................................ 25

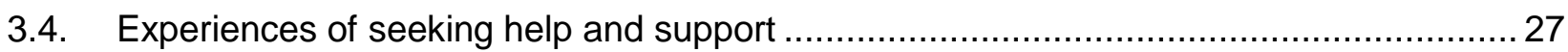

3.5. What would make it easier to access energy advice and support? .............................. 30

4. Stakeholder co-production workshop: sharing findings, developing ideas .................. 32

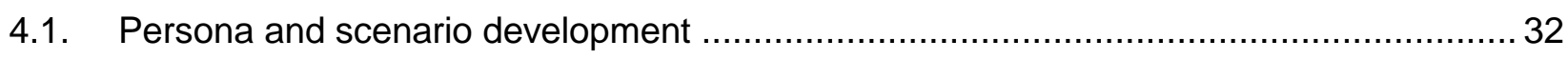

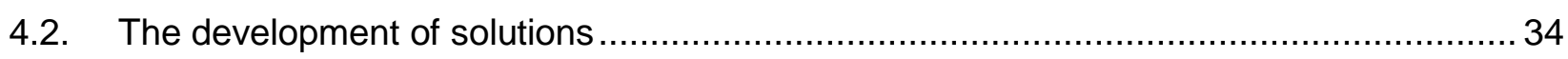

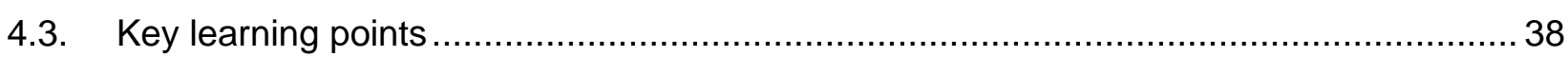

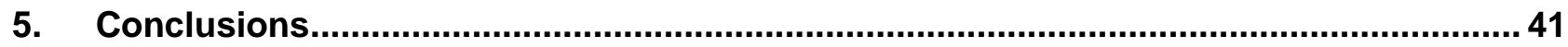

5.1. Equitable access to energy advice and services................................................... 41

5.2. Experiences of energy advice and how to improve them ........................................ 42

5.3. Reaching more hard to reach and vulnerable consumers ........................................ 43

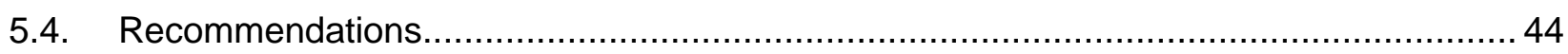

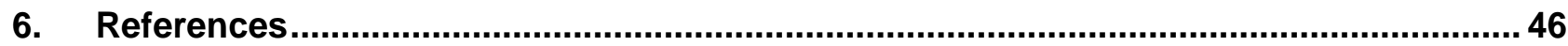




\section{Executive Summary}

\section{Introduction}

This project was funded by the Higher Education Innovation Fund (HEIF) and ran from 2016 to 2019. It was led by the Centre for Regional Economic and Social Research (CRESR) at Sheffield Hallam University in partnership with Citizens Advice. The project was also supported by a Stakeholder Reference Group (SRG) of policy makers, practitioners and academics including the Department of Business Energy and Industrial Strategy.

Funding was sought on the basis that the best ways to engage with the huge diversity of hard to reach energy users in the UK are under researched and their experiences poorly understood and their voices rarely heard. The project also recognised the imperative to engage more effectively with energy users as energy markets threaten to become increasingly unpredictable due to technological change and Brexit, the impacts of which are likely to be felt most acutely by the most vulnerable in society.

\section{Project overview}

The methodology underpinning the project has four components, as follows:

- A review of current thinking, policy and practice in relation to providing energy advice to the hard to reach.

- Qualitative research with citizens panels of hard to reach energy users in Bristol and Sheffield.

- A co-production workshop with the SRG to share findings and develop ideas.

- The development of conclusions and recommendations for policy and practice.

\section{Providing energy advice to the hard to reach: a review}

Understanding 'hard to reach': We argue that the term 'hard to reach' is context specific and cannot be described by a single list of groups likely to miss out on advice services. We also focus agency on service providers failing to make sure their services are inclusive rather than suggesting it is the characteristics of certain people that make their engagement with services difficult. However, we do identify 4 broad groups for whom energy advice needs to be tailored, including: those who are 'new to this', those undergoing 'big lifestyle change', those for whom life is a 'balancing act' and those who 'can't do this alone'.

Vulnerability: We highlight the current understanding of vulnerability as a dynamic, situational concept and welcome Ofgem's work to incorporate this understanding into its regulation of energy companies. We identify three types of vulnerability that can affect energy consumers: financial, health and capacity related and location-based. We consider vulnerability and fuel poverty, though closely related, to be two different concepts and think that policies and programmes should reflect this.

Understanding energy advice: We note that independent advice providers conceive advice as an independent, impartial form of support that helps people find the best solution for their needs. However, people facing problems with a service or good will often first seek to resolve the issue 
with the provider of that good or service. This is also often considered 'advice', although independent providers may dispute this. This report adopts the looser meaning of the term, not least because for many people in vulnerable circumstances this is the only support they will receive. It is therefore essential that service providers make sure support is inclusive and accessible.

Classifying energy advice: We identify four types of energy advice: reducing energy costs, reducing energy demand and improving the effectiveness of energy used, increasing income and consuming energy services. We suggest that the providers of independent energy advice fall into two camps: those focusing on energy efficiency and those focusing on energy markets. We stress the importance of joining up energy advice with other forms of advice, particularly for people with multiple problems for whom energy advice may not be their most pressing need.

Trends in energy advice: We note that the provision of energy market advice in England and Wales is fairly extensive, both at the local level and at the specialist second tier level (those taking referrals from other advice providers). While there is still room for improvement, this contrasts with the provision of energy efficiency advice where there has been a notable decline in recent years. In many parts of England and Wales, there is no telephone advice, let alone face to face advice. In these areas people can only access energy efficiency advice through a government website. This excludes many consumers in vulnerable circumstances. We consider that this trend undermines government policy priorities outlined in the Clean Growth Strategy and Fuel Poverty Strategy. However, we note that the growing emphasis on the health benefits of energy efficient homes may help reverse this trend.

Legal and regulatory protections: We review the various legislative, regulatory and selfregulatory protections in place to support consumers in vulnerable circumstances. We welcome such Ofgem initiatives as incorporating a vulnerability principle within supplier licence conditions and its intention to introduce tougher compliance and enforcement action. We also welcome the proposals of the Commission for Customers in Vulnerable Circumstances (CCVC) to drive up suppliers' standards for consumers in vulnerable circumstances. However, we are disappointed that neither Ofgem nor the Commission have addressed the suppliers' delivery of the Energy Company Obligation (ECO) energy efficiency programme. Our recommendations make proposals for rectifying this.

\section{Findings from the Citizens Panels}

We worked through trusted gatekeeper organisations and used snowballing techniques (where one respondent recommends another to speak to) to engage the hard to reach (Sadler et al, 2010). These techniques allowed us to recruit 26 individuals to take part in semi-structured qualitative interviews lasting up to 40 minutes each.

\section{Who did we speak to?}

The resulting sample represented a good mix in terms of gender and age but less so in relation to ethnicity (18 of the 26 participants were White British). More females participated than males (15 females and 11 males) and the 40-50 ( $n=7)$ and 50-60 (n=7) age groups had greater representation than other age groups. However, we did secure 5 participants in the $60+$ age group and 4 in the 30-40 age group. Only one participant was aged between 20 and 30 and only one was over 80 . In terms of tenure, 15 participants were in social rented accommodation of various sorts and the remaining 11 were privately renting.

Each participant identified multiple vulnerabilities that they felt affected them- the most common of which were related to low income, mental health problems and social isolation. As a result of the research being conducted in an urban context, those facing location related vulnerabilities were underrepresented. 


\section{The nature of the energy related problems experienced}

Respondents were asked to describe any energy related issues they were experiencing or had experienced in the past. All of those we spoke to were experiencing significant energy related difficulties despite not having been recruited on this basis. The majority of these problems related to concerns about the affordability of energy and homes that were cold and difficult to heat. Often participants were experiencing several issues in tandem reporting problems with cold homes, energy debt, under-heating and struggling to understand bills, tariffs and meter readings as well as a lack of confidence or capacity to seek help. It was clear in many cases that the affordability problems reported reflected wider difficulties associated with a low income. Many participants identified energy problems that were linked to their landlord (whether private or social). Primarily being a tenant caused problems when it came to trying to resolve energy problems but in some cases, private landlords were identified by respondents as causing or frustrating their energy problems.

\section{Experiences of seeking help and support}

17 of the 26 respondents had sought help with the energy problems they were experiencing. Of those who had sought help, 12 had turned to their energy supplier and five to independent advice providers. Most of those seeking help had approached their energy supplier in response to a communication they had received or because they perceived that it was the only way to resolve their problem. All of those who had sought advice through independent providers reported positive experiences but in line with the findings of the CCVC, most of those who had approached their energy supplier reported poor treatment and said they did not trust their energy supplier. It was widely commented that energy suppliers showed no sensitivity to individual circumstances and preferences when dealing with their customers and overwhelmed them with information and questions.

"I don't like the lack of connection, you just feel as if everything is being done by robots. I think what is really unfair is the way that communications are working with everybody is all geared to the young and new technology I think they should keep the options open so that it's not just a digital world... I think it's being pushed at the expense of people who can't access it easily and I think that is really bad. They are anonymous, they are not real." (Valerie, 83, in the early stages of dementia)

There was also evidence of 'negative feedback loops' in relation to exchanges between participants and energy suppliers. Participants reported that they would often enter into the conversation in an anxious state because they anticipated problems and/or because making the call pushed the limits of their confidence. This anxiety would then frequently lead to heated exchanges or be interpreted by the person taking the call as hostility and the call may even be terminated before a resolution was found.

"I have a panic attack when I pick up the phone to talk to them. Half the time, when you're getting het up you are trying to explain to them something and they are not understanding for one reason or another and then you get mad because of it and they put down the phone." (Sophie, 41, former rough sleeper)

\section{What would make it easier to access energy advice and support?}

Of the 26 respondents, 23 would prefer face to face advice. Over half of those calling for face to face advice felt that shops or other premises in accessible locations would be the best option with the rest suggesting that home visits would be more effective.

Face to face advice was felt to improve the chance of being heard and understood. Complex situations can be explained more easily in this context because it is easier to share documents and to bring someone along for support. 
"It's better that way because you know you're going to get somewhere. They can say what they want over the phone but face to face is better because then you know it's coming from the mouth and not coming from over a phone, you can actually see the person's language, you can actually see if they are being honest and truthful in what they say and do. It's not easy to do it over the phone; it's like disbelief when it's over phone...you can't see what body language it is." (Caroline, 41, disabled, living in social housing)

Those who advocated home visits felt that they would enable advice providers to reach a greater breadth of people as they remove any issues around mobility or travel; reduce anxiety as they are in a familiar setting and enable the occupant to convey the problem more easily. A small number of respondents felt that over the phone advice would be acceptable with some modifications to the current system including the eradication of push-button menus; free phone numbers and fewer transfers of callers between departments requiring them to explain their situation again. It was also important to participants that they were not hurried and there was also a call for the use of simple, uncomplicated language.

Despite trust in energy companies being universally low, the majority of participants who had sought help with their energy problems had turned to their energy suppliers. Many participants found it difficult to navigate the energy advice landscape and several participants stated that their own family was their most trusted source of support.

\section{Recommendations}

At the final meeting of the SRG we shared some of the findings from the citizens panels and used co-production techniques to work with those present to develop solutions to the problems experienced by participants. Our recommendations build upon the themes emerging from the workshop and our review of current policy and practice.

\section{Review of current policy and practice}

- $\quad$ Energy companies and other service providers should take a proactive approach to making sure everybody has access to services and take positive action to address the needs of those currently missing out.

- The UK government should update the statutory provisions enshrined within the Utilities Act for addressing the needs of consumers in vulnerable circumstances. These should reflect Ofgem's current approach to understanding vulnerability and such energy market developments as the much larger number of energy companies, smart meters and decarbonisation policies.

- $\quad$ Ofgem should encourage all energy companies to meet the BSI inclusion standard BSI 18477, at the very least, with respect to supporting consumers in vulnerable circumstances. Ofgem should also seek assurances from energy companies that they have procedures in place to meet the service delivery standards set out in the Equalities Act.

- Energy companies should develop new approaches to understanding the experiences of consumers in vulnerable circumstances and use these to improve service delivery, e.g. through commissioning independent research, supporting outreach engagement activities and working with intermediary groups in close contact with such consumers.

- $\quad$ Ofgem should monitor the extent to which the Energy Company Obligation (ECO) is reaching specific groups of consumers in vulnerable circumstances.

- The introduction of a state-funded energy efficiency scheme with explicit inclusion objectives to complement ECO would improve access for hard to reach households to energy efficiency measures. Irrespective of this, the UK government and Ofgem should reform the framework that governs the delivery of ECO such that it better meets the diverse needs of consumers in vulnerable circumstances. 
- Trusted intermediaries, such as independent referral services working with front line health and other workers, can play a valuable role in making sure energy efficiency and other energy support reaches consumers in vulnerable circumstances. This is a key recommendation of the NICE guideline, NG6. The NHS, Public Health England and relevant government departments should make sure that such referral services are properly funded and integrated with local health and other service provider structures.

- $\quad$ The UK Government should make sure that everybody has access to quality face to face local energy market and energy efficiency advice, including home visits for the most vulnerable, which complements telephone and web-based advice services. Existing energy advice programmes, such as Big Energy Saving Network and Energy Best Deal Extra which has proved effective at reaching consumers in vulnerable circumstances, should put more emphasis on providing energy efficiency advice.

- Independent advice providers and accreditation bodies should establish a series of minimum standards for energy advice, building upon the NEA level 3 energy training.

\section{Stakeholder panel workshop}

- Work through professionals embedded in communities: such as health professionals (district nurses, midwives), housing officers, repair teams etc. They have skills in engaging with vulnerable individuals and are more likely to be trusted.

- Embed support with home energy problems into the routine management of chronic conditions and hospital discharge. Early access to support may obviate a proportion of hospital admissions and lead to improvements in chronic conditions.

- Work with agencies taking a preventative approach: including the Fire and Rescue Service (through homes safety checks) and Public Health departments which may have resource and experience to contribute.

- Work with people's existing motivations: for example, if food and/or health are of importance to households with young children then energy advice initiatives should work through these agendas.

- Be alert to energy issues that aren't perceived as such. Problems bound up with energy issues may not be perceived this way by those experiencing them. For example: respiratory problems may not be linked to a cold home and difficulties affording food may not be considered in the context of high energy bills.

- Use general financial concerns as a conversation starter: issues with debt are the most common driver of people making contact with advice agencies. Energy advice needs can often be identified through these broader conversations.

- $\quad$ Talk to everyone: consider 'hanging around' at key events with a wide appeal such as flu clinics and aiming to talk briefly to everyone in attendance.

- Apply the principles of Making Every Contact Count (MECC) in an energy advice context. MECC views the millions of routine engagements that various agencies have with their client base on a daily basis as an opportunity to pass on (brief) messages about healthier lifestyles. Brief messages about the importance of keeping warm at home and seeking help with obstacles to this could be embedded into routine contacts made by energy suppliers and advice providers on the same basis. 


\section{Introduction}

In 2016 the project team secured funding through the Higher Education Innovation Fund (HEIF) to undertake a project which brought together existing knowledge and fresh empirical insights into how best to engage with so-called 'hard to reach' energy users in relation to the provision of energy advice. By building a rapport with a panel of individuals who might be deemed hard to reach - and who would not typically engage in a research project - we were able to understand their previous experiences of engaging with energy services and advice (if they had any); the barriers they experience to doing so and what would make it easier for them to access effective support with energy related issues in future.

Funding was sought on the basis that the best ways to engage with the huge diversity of hard to reach energy users in the UK are under researched and their experiences poorly understood and their voices rarely heard. The project also recognised the imperative to engage more effectively with energy users as energy markets threaten to become increasingly unpredictable due to technological change and Brexit, the impacts of which are likely to be felt most acutely by the most vulnerable in society.

The aim of this study was to achieve several things, as follows:

- It has drawn together and summarised key debates and thinking on hard to reach groups in an energy services and advice context, considering how they are defined and current good practice in engaging them (see Chapter 2).

- It has brought to life the experiences and perspectives of hard to reach groups through new, first hand insights from a panel of 26 citizens who self-identified as facing a range of vulnerabilities and whose circumstances and characteristics meant they were exposed to a range of energy related problems yet often missed out on advice and support (see Chapter 3).

- It has applied innovative processes for developing recommendations, good practice principles and fresh ideas about how to engage hard to reach groups in energy advice by using persona and storyboard techniques developed by the National Institute for Health Research (NIHR) (see Chapter 4).

- It has provided a set of recommendations aimed at improving the inclusivity of energy advice and the quality of service experienced by hard to reach consumers (see Chapter 5). 
- It has stimulated debate and interest in the plight of hard to reach groups in an energy context in the UK and internationally and provided inspiration for future projects exploring this important issue. It has contributed knowledge to key international projects looking at this and related issues including the Solutions to Energy Poverty (STEP) project funded by the European Commission and the recently launched TCP on hard to reach energy users led by Dr Sea Rotmann.

\subsection{Terminology}

Advice: Early on in the project, it became apparent that the term 'advice' may be interpreted in a variety of ways. Citizens Advice, in common with all independent advice providers, conceives advice as an independent, impartial form of support that helps people find the best solution for their needs. People facing problems with a service or good will often first seek to resolve the issue with the provider of that good or service. They might refer to the solutions offered by providers as 'advice', as might providers themselves. Of course, providers should have procedures in place for addressing issues that are effective, inclusive and responsive to consumers' needs without consumers having to seek advice from third parties. However, independent advice providers will not generally consider this as providing 'advice'. In recording people's interactions with both service and advice providers, this report has adopted the looser meaning of the term 'advice' used by consumers and service providers.

Hard to reach: This project does not subscribe to a specific definition of hard to reach, recognising the dynamic nature of the concept and the fact that households or individuals identified as hard to reach will vary between contexts. This argument developed in more detail in Chapter 2. Instead, we based our approach on working with those who self-identify as facing a range of vulnerabilities and whose circumstances and/or characteristics present obvious barriers to accessing advice and support in relation to energy issues.

\subsection{Project overview}

This project was led by the Centre for Regional Economic and Social Research (CRESR) at Sheffield Hallam University in partnership with Citizens Advice- the UK's largest advice provider.

The project was also guided and supported by a Stakeholder Reference Group (SRG). This comprised policy makers, practitioners and academics with a remit around or interest in understanding hard to reach energy users and engaging with them more effectively. SRG members included representatives of: The Department for Business Energy and Industrial Strategy (BEIS), Citizens Advice, the Energy Saving Trust, the Eaga Charitable Trust, the Universities of Sheffield and Salford, the $\mathrm{NIHR}$ as well as a number of independent practitioners, smaller organisations and community groups with relevant experience. The major energy suppliers British Gas and EoN also contributed to the SRG in the early stages of the project.

The SRG provided input into the project over the course of three events. The first event coincided with the launch of the project and was used to confirm the aims and methods and to scope issues around definitions of hard to reach groups. The second event involved feeding back the findings from the citizens panel to the SRG and debating their implications, whilst the third and final event (facilitated by NIHR) focussed on developing recommendations to put forward to the policy and practice community. 
The methodology underpinning the project had four distinct and sequential components, as outlined in the diagram below. The remainder of the report is structured in line with these activities.

Figure 1.1: Overview of methods

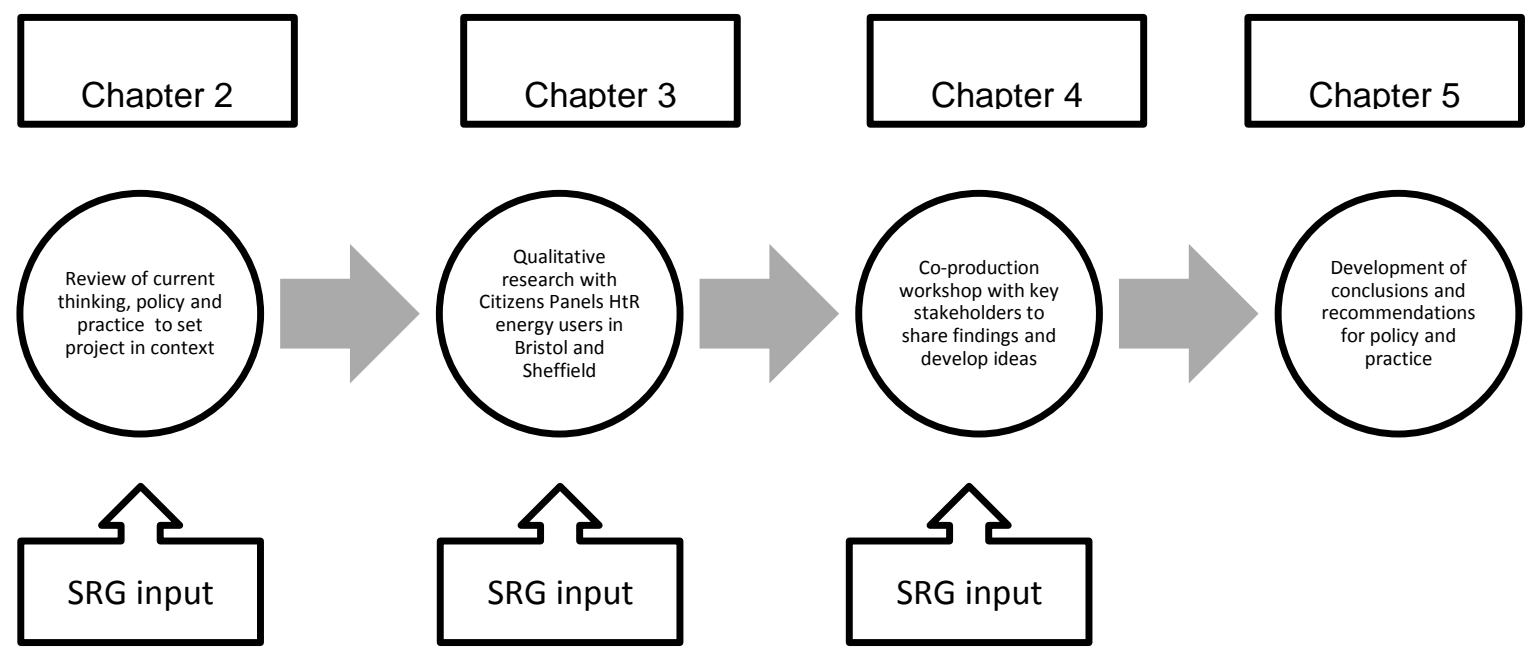




\section{Providing energy advice to the hard to reach: a review of current thinking, policy and practice}

\subsection{Who are the 'hard to reach'?}

The terms 'hard to reach' and 'hard to hear' are widely used by health and social care service providers, by national and local governments wanting to make sure everybody has a say in consultations or by any organisation providing a service intended for the general public. However, there is a distinct lack of clarity about the meaning of these terms (Freimuth \& Mettger, 1990). They are often used inconsistently to describe any form of minority group, such as homeless people, drug users, disabled people, recent migrants, private renters or even young or old people in general (Cardiff Council, 2009).

Many commentators argue that using an umbrella term such as 'hard to reach' implies a homogeneity within groups that does not exist (Brackertz \& Meredyth, 2008). It also implies there is something about such people that makes their engagement with services difficult, rather than service providers failing to make sure their services are inclusive.

Others argue that the term 'hard to reach' is context specific and there is no single list that can define groups of people that are 'hard to reach' (Nottinghamshire Council Council, 2007). An alternative term sometimes used in care and social services is 'seldom heard' (IRISS, 2011). Factors that contribute to people being seldom heard in care include disability, ethnicity, sexuality, communication impairments, mental illhealth, homelessness and geographic isolation (ibid).

While the 'context specific' nature of engaging 'hard to reach' households suggests there are numerous and wide ranging barriers to engagement, it is possible to identify certain overarching barriers that can be applied to almost all groups (Cardiff Council, 2009). These include:

- methods of involvement;

- physical barriers;

- attitudinal barriers; 
- financial/resource problems;

- cultural issues;

- $\quad$ gender;

- timing;

- $\quad$ perceptions of relevance.

(Not that this list has been slightly adapted for the purpose of this research).

\subsection{1. 'Hard to reach' and energy advice}

Following the argument that 'hard to reach' is context-specific, Citizens Advice and 'grassroots' organisations working with specific communities have developed the following typology of 'hard to reach' households with respect to providing energy advice (Citizens Advice internal publication).

\section{Target user groups for energy advice}

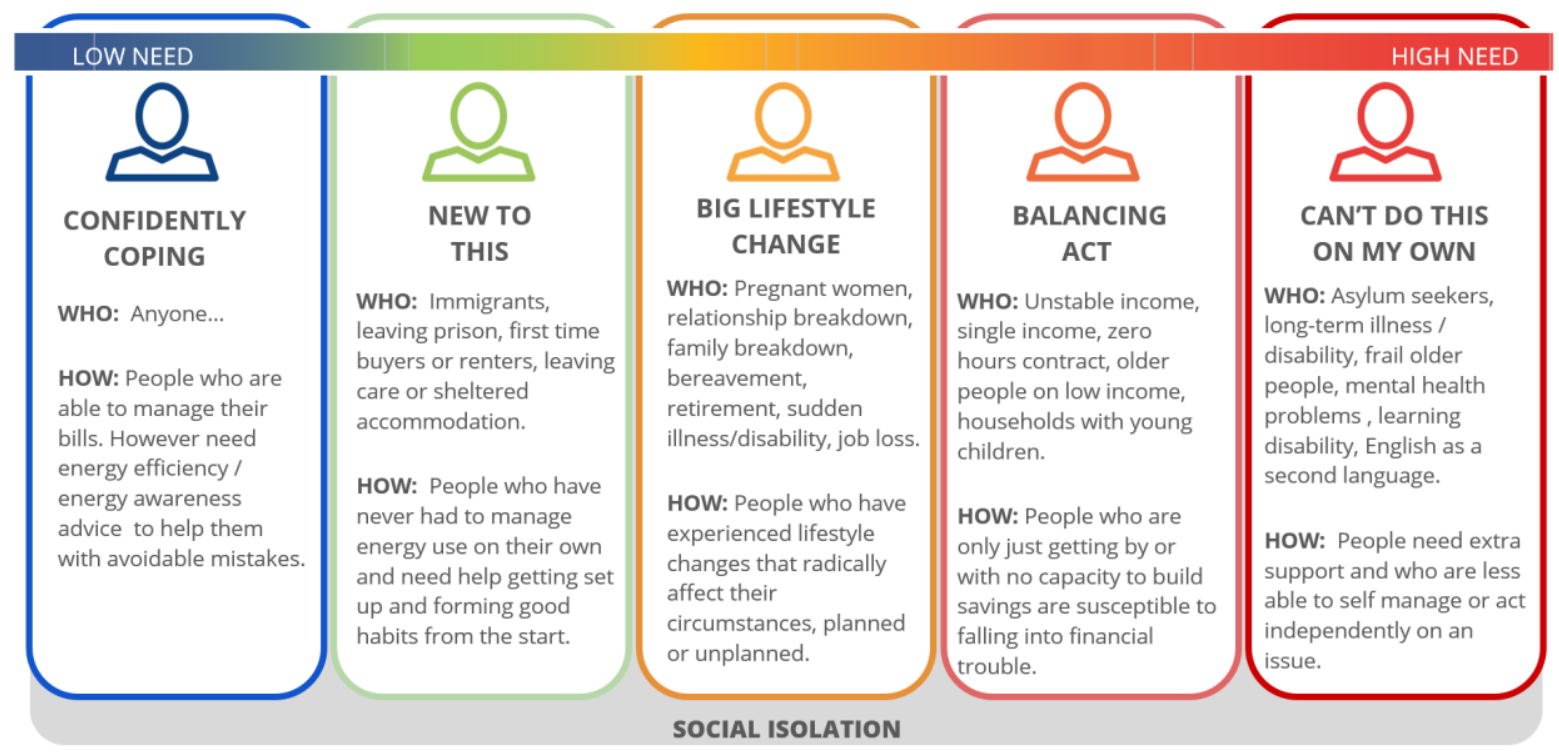

While this is a useful starting point with respect to both particular groups that might need energy advice and to the type of advice they might require, there are still groups omitted. For example, many low income rural households miss out on advice because of lack of local advice providers, problems associated with non-mains gas heating fuels and rural housing or cultural factors associated with rural communities that can lead to reluctance to seek advice (Baker et al, 2008). Such cultural factors can exist in other communities as well.

\subsubsection{Vulnerability}

The concept of 'vulnerability' is central to understanding 'hard to reach' with respect to energy services and energy advice. Households in vulnerable circumstances are often the same as those described as 'hard to reach' and there are similar debates on how vulnerability should be understood.

For example, Ofgem now emphasises the situational aspects of vulnerability and the notion that vulnerability can be temporary for some consumers. Ofgem defines vulnerability as 'when a consumer's personal circumstances and characteristics combine with aspects of the market to create situations where he or she is: 
- $\quad$ significantly less able than a typical consumer to protect or represent his or her interests in the energy market; and/or

- $\quad$ significantly more likely than a typical consumer to suffer detriment, or that detriment is likely to be more substantial' (Ofgem, 2013).

The term 'aspects of the market' points towards market failures or structural factors as giving rise to consumer detriment, that is energy suppliers and the institutional arrangements in which they operate give rise to vulnerability. Or as Stearn argues: 'consumer vulnerability cannot simply be seen as consumers' failure to engage with the market when markets are failing to engage with consumers' (Stearn, 2016).

However, the phrase 'less able' could be interpreted as suggesting 'failings' on the part of certain consumers, rather than placing culpability on service providers for failing to ensure inclusivity. In effect, Ofgem's definition encompasses both structural and individualistic factors as giving rise to vulnerability.

The dynamic and often temporary nature of energy vulnerability is reflected in Atherton's explanation of vulnerability that 'anybody can find themselves in a situation (of suffering detriment) but examples of high risk consumers could be people living on low incomes, pensioners, those that are chronically sick or living with a disability, or people living in rural areas' (Atherton, 2018).

The Commission for Customers in Vulnerable Circumstances identified three types of vulnerability that can affect energy consumers:

1. Financial vulnerability - essentially those consumers whose income is insufficient to cover their essential household bills, including energy.

2. Health and capacity-related vulnerability - consumers whose capacity or condition prevents them from accessing services or engaging with the energy market.

3. Location-based vulnerability - rural consumers and those reliant on district heating face a range of vulnerabilities arising from their location (Commission for Customers in Vulnerable Circumstances, 2019).

\subsubsection{Fuel/energy poverty}

A related concept that adds further complexity to understanding 'hard to reach' and 'vulnerability' within energy services is 'fuel poverty'. Fuel poverty is broadly understood as a combination of low income, high fuel costs and poor energy efficiency of housing, heating systems and appliances. However, operational definitions of fuel poverty, i.e. definitions that allow the issue to be measured and policy impact assessed, vary across the different nations within the UK. Attempts to produce an international, measurable definition of fuel/energy poverty have proved even more difficult (Thomson et al., 2017).

The contribution of poor energy efficiency standards to fuel poverty led Fahmy to distinguish fuel poverty from more general poverty in the following way: 'for any given level of income, households and individuals have an unequal capability to convert income into adequate warmth (and energy services) which is distinct from, and additional to, those deprivations associated with insufficient income itself (Fahmy, 2011).

Some commentators have more recently sought to move understanding of fuel poverty away from technical and economic metrics of housing standards and energy efficiency (Middlemiss \& Gillard, 2015; Scottish Government, 2017). Instead, they 
focus on exposure to fuel poverty, sensitivity to its impacts and a household's adaptive capacities for coping with it (e.g. Mould \& Baker, 2017). Such approaches focus on fuel poverty as a matter of social justice and bring it more into mainstream discourse on poverty and inequality in general. For example, Bouzarovski defines fuel poverty as: 'a condition in which a household lacks a socially and materially necessitated level of energy services in the home' (Buzar, 2007). This approach is more in line with the Poverty and Social Exclusion 'consensual' approach which defines poverty as 'those whose lack of resources forces them to live below a publicly agreed minimum standard' (Gordon et al, 2013).

Notwithstanding debates over how fuel poverty is understood, it is important to recognise that fuel poverty and energy vulnerability, while related, are two distinct issues. They require different metrics for definition and different measures to tackle them, although many will overlap. As noted above, all energy consumers are at risk of facing consumer detriment, and are thus 'vulnerable' when they do, for example because of a change in their circumstances which may be transient or long term. While low income is an important risk factor for vulnerability, there are many others, for example those relating to ill-health or disability.

Low income is central to the concept of fuel poverty. This is explicit in the Low Income High Costs definition of fuel poverty in England and the new definition in Scotland within which the Minimum Income Standard is a central component (Hills, 2012; Scottish Government, 2017). Consumers in vulnerable circumstances are more likely to live in fuel poverty, particularly if they have poor health or long term disability. However, there are many who do not live in fuel poverty but face other forms of detriment. They nevertheless should still have rights to equitable receipt of energy services.

\subsection{What is energy advice?}

In defining 'energy advice' it is first necessary to clarify the term 'energy' and 'energy services'. For the purposes of this research, the terms refer to:

- Domestic consumers only.

- The supply of energy to homes, principally electricity and gas but also oil, LPG, solid fuel and district heating.

- Services that help reduce the demand for energy, for example insulation, efficient heating and efficient appliances.

- It does not include redress, that is the structures and procedures in place to compensate consumers who have experienced detriment due to the poor practice of a service provider. However, advice may often lead to consumers receiving compensation.

With respect to 'energy advice', as highlighted in the introduction, the term has different interpretations in different sectors. In recording people's interactions with both service and advice providers, this report has adopted the looser meaning of the term 'advice' used by consumers and service providers, rather than that adopted by advice agencies (see note on terminology in Chapter 1). Service providers in this context include fuel suppliers, energy efficiency, heating and microgeneration contractors, builders or sales staff. All of these agencies represent important sources of information for a large number of energy service consumers and will typically be the first port of call should any issue arise. 


\subsubsection{Classifying energy advice}

A useful typology of the different forms of energy advice is summarised in the Citizens Advice energy advice strategy (Citizens Advice, 2017). While this focuses on energy advice provided by independent agencies, some of the examples could also apply to service providers, for example, information about a cheaper tariff within the same company (although the provider is highly unlikely to provide information about a cheaper tariff with another company), or registration on the company's Priority Service Register:

\section{i. Reducing energy costs}

This encompasses advice that focuses on reducing the unit price of energy, for example by switching fuel supplier, tariff or bill payment method, e.g. Direct Debit, standard credit or prepayment in the case of gas or electricity. It can also refer to making best use of Economy 7 tariffs or switching to new time of use tariffs made possible through smart meters. It may also involve providing advice on claiming the Warm Home Discount - a $£ 140$ discount on electricity bills for eligible consumers.

\section{ii. Reducing energy demand and improving effectiveness of energy used}

This encompasses advice that focuses on improving the energy efficiency standards of housing fabric, heating systems and appliances, including advice on any grants or subsidies for more expensive measures. The latter also covers advice on support for microgeneration heat and power options, such as the Feed In Tariff and Renewable Heat Incentive. It also covers advice on behavioural measures, such as making effective use of heating controls, reducing unnecessary energy use and acting upon feedback information provided through smart meters and in-home displays.

Energy efficiency advice can play an important role in addressing condensation, damp, cold homes, unaffordable energy bills and the impact of such issues on health and well-being. Finally, it may incorporate advice associated with current tools to help people understand and improve energy efficiency standards, such as Energy Performance Certificates and appliance energy efficiency ratings.

\section{iii. Increasing income}

This encompasses advice on claiming fuel-related benefits, such as Cold Weather Payments and Winter Fuel Payments, and more generally on entitlement to benefits and tax credits or the minimum and living wage. It can also include advice on reducing debt repayment levels, both fuel and other debts, by negotiating manageable debt solutions.

\section{iv. Consuming energy services}

This refers to advice on consumer rights both with respect to general consumer law and those specific to energy supply (gas, electricity, off-gas fuels) or energy efficiency and microgeneration services. It can cover rights deemed through regulation, e.g. fuel suppliers' licence conditions, and those put in place through selfregulation, e.g. the Federation of Petroleum Supplier's consumer charter and code of practice for domestic heating oil consumers.

It covers advice to resolve problems, e.g. debt, disconnection, back-billing; helping consumers secure redress from energy, energy efficiency and micro-generation companies when things go wrong; raising tenants and landlords' awareness of minimum energy efficiency standard regulations in the private rented sector and making sure consumers on low incomes and in vulnerable circumstances exercise their rights for particular services. The latter includes services available through the 
gas and electricity Priority Services Registers or through the codes of practice for oil, gas, solid fuel and district/communal heating.

\subsubsection{Overview of the independent energy advice sector}

Providers of independent energy advice generally fall into two camps:

1. Those focussing on energy efficiency advice (the second category in the Citizens Advice typology above).

2. Those focussing on switching and energy market issues (the first and fourth categories in the Citizens Advice typology).

The third category of energy advice - increasing incomes - is more associated with generalist advice providers, such as local Citizens Advice or Age UK, although specialist energy advisers in both camps may also provide some advice in this area.

\section{Energy efficiency advice}

For many years, the UK government funded the Energy Saving Trust (EST) to coordinate the provision of energy efficiency advice across Britain. The EST contracted local and regional organisations to provide such advice and provided a range of complementary functions, such as marketing materials, technical expertise and self-help home energy checks. Local organisations often supplemented EST funds with funding from councils, fuel suppliers, charitable trusts and other bodies to provide more bespoke local services, such as home visits and community outreach.

The EST essentially aimed to make sure that everybody had access to a minimum standard of quality energy efficiency advice, while local organisations often sought to improve upon this by targeting specific groups of households with tailored information and/or offering home visits to particularly vulnerable people. National Energy Action is the main provider of training for independent providers of energy efficiency advice, with its accredited energy awareness course ${ }^{1}$ considered the minimum standard required for advisers working in this field.

The UK Government stopped funding EST's network of regional advice centres in England and Wales in 2012 and replaced them with a single national telephone advice service, the Energy Saving Advice Service (ESAS), also run by EST. The UK government later stopped funding ESAS in April 2018 and replaced it with a 'digitally assisted' Government website. ${ }^{2}$ The Scottish Government continues to fund a network of 5 regional EST advice centres, supplemented with a number of more local outreach centres.

A number of local organisations continue to provide energy efficiency advice to people in their area with funding from councils and other sources. In some cases, local authorities provide direct energy advice themselves. The larger advice centres will often provide face to face advice, home visits and/or community outreach services to specific groups of clients in vulnerable circumstances.

However, there is no longer a national energy efficiency telephone advice service in England and Wales, nor coordinated provision of local advice services designed to make sure everybody can get a minimum standard of advice. In effect, access to specialist energy efficiency advice at a local level is now very patchy and dependent on local, often insecure funding.

\footnotetext{
See: www.nea.org.uk/training/course-outlines/level-3-award-in-energy-awareness-6281-01/

${ }^{2}$ See: www.simpleenergyadvice.org.uk.
} 
There are no local energy efficiency advice centres in many areas of the country local residents now have to rely solely on the 'simple energy advice' website. This is of particular concern for people in vulnerable circumstances since there is extensive evidence that many do not access advice via the internet and prefer either face to face or telephone based advice (Boardman \& Darby, 2000). Furthermore, there is evidence that face to face advice is more likely to result in advisers identifying other client needs beyond the initial presenting problem (Baker et al, 2019).

\section{Energy market advice}

Citizens Advice is now the main provider or coordinator of energy market advice through the following programmes:

Consumer helpline ${ }^{3}$ (formerly known as Consumer Direct) - a statutory telephone advice service, funded by the UK government, that includes an extensive energy element. Advice tends to focus on complex issues relating to energy supply, such as contract law.

Extra Help Unit (EHU) ${ }^{4}$ - a statutory second tier telephone advice service, funded by the UK government, that provides advice to consumers in vulnerable circumstances, particularly those facing disconnection or complex problems with their suppliers. The EHU takes referrals from the Consumer helpline, MPs and other political representatives.

Big Energy Saving Network (BESN) ${ }^{5}$ - Citizens Advice is funded by the UK government to coordinate and manage a network of local advice agencies (both local Citizens Advice and other agencies) to run group training sessions and provide simple energy advice to individuals over the winter months. While advice is intended to cover energy efficiency as well as switching, the emphasis is mainly on the latter. BESN focuses on low income consumers and was originally established to address the low switching rates among such consumers. A major issue for BESN providers is that funding and provision only covers the winter months, yet clients will often want advice at other periods of the year.

Citizens Advice also coordinates an annual Big Energy Saving Week to encourage local awareness raising and focussed publicity.

Energy Advice Programme ${ }^{6}$ (EAP) - Citizens Advice receives funding from a number of fuel suppliers, via the Warm Home Discount industry initiatives scheme, to provide in-depth one to one energy advice to low income consumers. Again while advice is intended to cover energy efficiency as well as switching, the emphasis tends to be on the latter. It may also cover related energy issues such as fuel debt, hardship payments and eligibility for the Warm Home Discount and Priority Services Register. Like BESN, EAP is only funded and provided over the winter months. Funding also has to be re-negotiated with suppliers every year, which reduces certainty of provision.

\subsubsection{Trends in energy advice provision}

In broad terms, the provision of energy efficiency advice in England and Wales has declined while provision of energy market advice, particularly with respect to advice

\footnotetext{
${ }^{3}$ See: www.citizensadvice.org.uk/consumer/get-more-help/if-you-need-more-help-about-a-consumer-issue/

${ }^{4}$ See: https://ehu.org.uk/

5 See: www.citizensadvice.org.uk/about-us/how-we-provide-advice/our-prevention-work/BESN/

${ }^{6}$ This was formerly known as the Energy Best Deal extra programme (see Williams \& Whyte (2018) for an evaluation of the programme).
} 
on switching suppliers, has increased. This decline in efficiency advice appears to mirror the decline in UK government support for energy efficiency measures since 2010 (Citizens Advice, 2019) - see Section 3.2.

The Government's apparent prioritisation of support for switching advice in ahead of energy efficiency advice appears contradictory, given that both its fuel poverty strategy and clean growth strategy focus on the long term benefits of improving home energy standards, for example improved health and quality of life, reduced fuel poverty and reduced energy consumption and carbon emissions (HM Government, 2017 \& 2019). Yet consumers' access to local energy efficiency advice would appear to depend on which part of the country they live in.

\section{The health case for improved energy standards}

One factor that has started to encourage a limited growth in local energy efficiency advice, and energy advice in general, is the involvement of public health and health sector agencies in 'cold home referral services' with energy advice forming a central component of this. The NICE guideline, NG6, on tackling excess winter deaths and the health risks associated with cold homes has helped drive this (NICE, 2015). The guideline recommended that all local health and wellbeing boards should establish single point of contact health and housing referral services. Front-line health and other workers should refer people at risk of cold-related illness to the service which in turn should make sure people receive tailored support (ibid).

The NICE guideline identified certain groups as particularly vulnerable to the cold. This might be due to medical conditions, such as heart disease; a disability that might stop people moving around to keep warm or make them more likely to develop chest infections; or personal circumstances, such as being unable to afford to keep warm enough (ibid).

NICE envisaged that support would primarily take the form of energy efficiency improvements and grants for this, plus advice on such matters as benefit entitlement, registration on fuel suppliers' Priority Service Registers and avoiding the health risks of living in a cold home (ibid). Again, response to the guideline has been very patchy with many areas still yet to establish a referral service (Ruse \& Burroughs, 2016). Engagement of health workers in referral services has also sometimes proved difficult, due to other pressures on their time and in some cases data protection issues (Citizens Advice, 2018).

The UK government has sought to encourage more local initiatives through supporting the development of cold home toolkits for local authorities and health agencies, sponsoring NEA to carry out an extensive study of health sector engagement in fuel poverty and cold home initiatives and establishing a cross agency fuel poverty and cold-related ill-health working group (Citizens Advice, 2018b; Ruse \& Garlick, 2018; and NEA, 2019).

However, there are no plans, to date, to re-establish a national or universal local energy efficiency advice service. Nor has the UK government put in place a publicly funded energy efficiency grant programme for England or taken other steps to address funding shortfalls for meeting its statutory fuel poverty targets. This is despite recommendations from its official advisory bodies, the fuel poverty committee and climate change committee, to improve the rate and depth of home energy improvements, particularly for low income households and social housing, and to introduce a publicly funded 'clean growth challenge fund' (Committee on Fuel Poverty, 2018). 


\section{Energy and other advice needs}

Many low income and vulnerable consumers face a wide range of pressures, budgetary constraints and housing problems. They will often put in place a variety of coping mechanisms to manage their budgets and/or vulnerabilities. However, it is a common experience of advice providers that people often only seek advice when:

- A wide range of problems have built up to apparently intractable levels, for example multiple debts.

- They experience an unexpected change in personal circumstances, such as losing a job, a death in the family or a separation/divorce.

- A crisis, such as a benefits sanction, illness, work drying up for those in insecure employment, household appliance break down, or receipt of an eviction notice.

Consumers will generally not consider energy advice a priority in most of these situations. Exceptions might include a boiler breaking down, an unexpectedly high fuel bill or a mounting fuel debt ${ }^{7}$. People will want help with their immediate problems, such as benefits, debt or housing advice, before being receptive to the sort of help that can be provided through energy advice. Energy advice can form part of a long term package of support but people in crisis will often consider other advice needs take priority over this.

This is an important consideration for energy advice providers. There may be situations when people in vulnerable circumstances are interested in energy advice without the stimulus of a crisis prompting this - it is possible that a focus on the health benefits is one such situation. But for many, it makes more sense when provided as part of a package of wider advice support (Citizens Advice Energy Advice Strategy).

\subsection{The essential nature of energy services}

Energy supply and warm, 'affordable to heat and power' housing are essential services in today's society. The Poverty and Social Exclusion Survey, for example, asks a representative sample of people to rank which necessities they consider for life in today's society (Gordon et al, 2013). Access to warm, dry housing is consistently ranked as one of the highest priority necessities. Similarly, the original establishment of a sector specific regulator for energy supply reflected this recognition of energy as an essential service. This entails a responsibility on suppliers of energy services - in effect energy suppliers, housing providers and energy efficiency services - to make sure everybody has equitable access to such services.

The essential nature of energy services places a responsibility on suppliers to make sure their services are inclusive and available to all sections of the community. It also implies proactive efforts to identify the specific needs of different groups and to make sure such groups are not overlooked or 'left behind' (Roberts, 2018). This will often require government and regulatory intervention to guarantee equitable access. Energy advice providers similarly need to encompass inclusivity and take particular efforts to reach all sections of the community. It is equally important that funders of energy advice recognise this.

\footnotetext{
${ }^{7}$ Debt advisers classify fuel debt as a priority debt. A priority debt is one that will result in serious consequences if the debt is not paid. In the case of fuel, this could lead to disconnection of supply.
} 
With this in mind, it is useful to consider the various legal and regulatory protections in place for energy service consumers in vulnerable circumstances, looking first at energy supply and then at energy demand.

\subsubsection{Energy supply}

\section{Legal and regulatory protections for consumers in vulnerable circumstances}

While UK governments have issued considerable legislation relating to energy over the past 15 years, the key legislation that set out the original legal and regulatory structure for the current energy market is the 2000 Utilities Act. $^{8}$ Key elements of the legislation include:

- The establishment of a single, economic regulator for the gas and electricity sectors (Ofgem).

- A new primary objective for the regulator to protect the interests of energy consumers, wherever appropriate, by promoting effective competition.

- A requirement on the regulator to have regard to the interests of low income consumers, the chronically sick, the disabled, pensioners and consumers in rural areas.

- A requirement on the regulator to have regard to guidance issued by the Secretary of State on the social and environmental objectives relevant to the gas and electricity sectors.

- $\quad$ Giving powers to the Secretary of State to make regulations to promote energy efficiency, the generation of electricity from renewable sources, and to provide for a cross-subsidy for the benefit of disadvantaged consumers.

The Utilities Act, as with previous legislation on the regulation of utilities, envisaged the energy regulator as independent of government. In brief, "independence is seen as a means to insulate regulation from politicians who are tempted to favour short term electoral advantage over long term policy goals, and recognises that politicians are likely to lack the technical expertise to make efficient policy choices" (Centre for Competition Policy, 2018).

The Centre for Competition Policy goes on to argue that regulatory independence has diminished during the 2000s. It attributes this in part to political concerns over rising energy prices and in part to lack of clarity over responsibility for addressing trade-offs involving distributional concerns, e.g. between affordability and decarbonisation (ibid).

\section{The respective roles of government and regulator}

The Energy Act 2013 attempted to clarify the respective roles of the regulator and government by making provision for a Strategy and Policy Statement. This enables the Secretary of State to set strategic priorities for the government's energy policy and is intended to have greater legal weight than the social and environmental guidance provisions of the Utilities Act. However, the government has yet to issue a Strategy and Policy Statement, despite this provision being on the statute book for over 5 years (Centre for Competition Policy, 2018).

Government policies that entail significant fuel company expenditure and hence additional costs for energy consumers are generally implemented through new

\footnotetext{
${ }^{8}$ Available at: $\mathrm{http}: / / w w w . l e g i s l a t i o n . g o v . u k / u k p g a / 2000 / 27 /$ notes
} 
legislation. Examples include the establishment of the electricity capacity market, ${ }^{9}$ updates to supplier energy efficiency obligations ${ }^{10}$ and the introduction of the Warm Home Discount scheme. ${ }^{11}$

With respect to consumers in vulnerable circumstances and on low incomes, the emphasis on promoting effective competition is of key importance. There can be tensions between policies to promote the liberalisation of energy markets and the sometimes detrimental impact of such policies on low income consumers (Thomas, 2008; Baker, 2001). For example, liberalisation can exacerbate wider social inequalities unless governments intervene to take countervailing action (ibid). However, while the consumer interviews conducted for this research reveal some of these tensions, discussion of the pros and cons of liberalisation is not a primary objective of this research.

\section{Ofgem's duties for consumers in vulnerable circumstances}

A key mechanism Ofgem uses to meet the Utilities Act requirement to have regard for low income, chronically sick and disabled consumers is through the inclusion of specific conditions in suppliers and distribution companies' licences designed to address vulnerability. These include:

- Maintaining a Priority Services Register of consumers in vulnerable circumstances; making sure communications are provided in accessible formats, conducting meter readings if the customer is unable to do so and annual gas safety checks for certain groups of owner occupiers.

- Requiring suppliers to take 'ability to pay' into account when calculating instalments for consumers in debt.

- Suppliers with over 50,000 customers must offer a wide range of payment methods, including cash and prepayment meters; any differences in price between payment methods must be cost-reflective (this was limited in 2017 with the introduction of the prepayment meter price cap).

- Rules on disconnecting properties where charges haven't been paid, e.g. suppliers must not disconnect certain vulnerable customers during the winter.

- A 'vulnerability principle', introduced in 2018, that requires suppliers to improve their identification of consumers in vulnerable circumstances and make sure they consider their needs.

Ofgem has taken further steps to encourage suppliers to address vulnerability more proactively. In 2013 , Ofgem published a vulnerability strategy that set out its five year plan for improving the services offered by fuel companies to consumers in vulnerable circumstances (Ofgem, 2013). Key components included:

- A new definition of vulnerability, as described in Section 1 above.

- Improvements to the Priority Services Register.

- Improving company practices to help identify and support vulnerable consumers, for example dealing with debt and disconnection.

- The establishment of an incentive and reward scheme for distribution companies to support consumers in vulnerable circumstances.

\footnotetext{
${ }^{9}$ See: https://www.gov.uk/government/collections/electricity-market-reform-capacity-market

${ }^{10}$ See: www.legislation.gov.uk/uksi/2018/1183/contents/made

11 See: http://www.legislation.gov.uk/uksi/2011/1033/contents/made
} 
At the time of this study, Ofgem is consulting on a new vulnerability strategy for the next five years (Ofem, 2019). Key proposals over and above those outlined in its original strategy include:

- $\quad$ Better support for prepayment meter consumers at risk of self-disconnecting with an expected outcome of reduced self-disconnections.

- A step change in suppliers' services for vulnerable groups, such that suppliers better tailor their customer services to consumers with specific needs.

- Tougher compliance and enforcement action to make sure energy companies comply with the protections for consumers in vulnerable situations.

\section{Self-regulatory initiatives in support of consumers in vulnerable positions}

This refers to 'voluntary' initiatives by fuel companies that go beyond regulatory requirements. In reality, self-regulation is generally most effective when companies take action to avoid the threat of formal regulation. Examples in the energy sector include:

- The 'safety net' agreed by the 6 largest gas and electricity suppliers by which they undertake to never knowingly disconnect a vulnerable consumer at any time of the year, thus going beyond the licence condition requirement outlined above (Energy UK, 2016a).

- The 'prepayment meter principles', agreed by most gas and electricity companies of all sizes, designed to improve safeguards and protections for prepayment meter consumers (Energy UK, 2016b).

- Several energy companies have voluntarily adopted the British Standard for inclusive services (BSI 18477), which aims to provide a gold standard for making sure services are accessible and vulnerable consumers are treated fairly (BSI, 2010).

- The code of conduct and consumer charter, both of which include provisions for consumers in vulnerable positions, agreed by members of the Federation of Petroleum Suppliers, the trade association for heating oil suppliers (FPS, 2013).

- The vulnerability customer charter agreed by members of the UKLPG, the trade association for LPG suppliers (Liquid Gas, 2017).

The Commission for Customers in Vulnerable Circumstances (CCVC)

In 2018, Energy UK, the trade association for gas and electricity suppliers, established an independent Commission for Customers in Vulnerable Circumstances to investigate suppliers' treatment of consumers in vulnerable circumstances and make recommendations for improvement. The Commission's report of its findings chime with many of the issues identified by the fieldwork for this research (Commission for Customer Vulnerability, 2019). Its recommendations, if implemented, could make a valuable contribution towards addressing these issues. We build on these in Section 5 below. It is therefore worth highlighting the Commission's work.

\section{Findings}

1. Inadequate and inconsistent treatment (by suppliers) of consumers in vulnerable circumstances: "there are far too many instances of poor treatment of customers in vulnerable circumstances by a sector that is seriously lacking in trust". Furthermore, "the protections currently in place... are primarily reactive measures to prevent specific issues being repeated. A gap exists for a forum 
that encourages proactive measures to drive up standards for customers in vulnerable circumstances."

2. Inadequate regulation and enforcement by the regulator: For example, a new company's ability to meet the needs of consumers in vulnerable circumstances is not currently central to it gaining a licence. Ofgem often took too long to follow up on evidence of poor supplier performance. There are also significant gaps in regulatory oversight, for example price comparison websites, automated switching services, heat networks and oil and LPG.

3. It is too difficult to access support: The impact of the Priority Services Register (PSR) is constrained by lack of awareness, obstacles to registration and lack of guarantee that registration on the PSR will trigger additional services or support.

4. Inflexible communication: Some suppliers do not provide a phone number for consumers to contact them, with one only offering an app-only approach. There was also evidence of some price comparison websites not meeting minimum website accessibility standards - a potential breach of the Equality Act.

5. Absence, or sporadic nature, of partnership between suppliers and public/third sector bodies: There is no requirement on suppliers to establish partnerships - beyond the mandatory signposting to Citizens Advice and the Energy Ombudsman.

6. The challenge of smarter energy: Smart technology creates opportunities for targeted advice and support, reducing self-disconnection among prepayment meter consumers and other benefits to consumers in vulnerable circumstances. However, many are concerned that such consumers will be left behind without concerted regulatory intervention.

7. Affordability: The report highlights the "sheer number of people in the UK struggling to afford basic costs of modern life". It highlights the fall in the real value of wages over the last 10 years, the impact of the benefits freeze and the increasing volatility in household income including for those in work.

\section{Key recommendations}

- $\quad$ Create an independently monitored Code of Conduct for suppliers to drive up standards of support for customers in vulnerable circumstances.

- Suppliers and price comparison websites should nominate a dedicated "vulnerability champion" on their Boards with responsibility for improving the delivery of services to vulnerable households.

- Strengthen Ofgem's licensing regime to ensure all suppliers operating in the market are equipped to support customers in vulnerable circumstances.

- $\quad$ Provide systematic training for all frontline staff to identify and proactively offer support to vulnerable households.

- Industry bodies should work together to raise awareness and the effectiveness of the Priority Service Register.

- Suppliers should make sure that a range of contact routes are available to customers, including freephone numbers and paper-based communication.

- Suppliers should develop and share innovative practice to monitor and tackle self-disconnection. 
- Strengthen and streamline partnerships between suppliers and charities to make sure people get access to all the help they need.

- Households served by heat networks and those using LPG and heating oil should get the same regulatory protection as those using gas and electricity.

- Introduce a social tariff for low-income vulnerable households after the current default price cap ends.

- The Government should introduce a state-funded energy efficiency scheme for England to help tackle fuel poverty, matching those already in place in Scotland and Wales.

\subsubsection{Energy demand}

\section{The legal and regulatory framework for energy efficiency services}

In broad terms, vulnerability is only taken into account for energy efficiency services delivered by statute. These include the Energy Company Obligation (ECO), which covers the whole of Great Britain, the Nest and Arbed schemes in Wales and the Home Energy Efficiency Programmes in Scotland. However, regulations governing housing energy efficiency standards in both the private and social rental sectors also play an important role, given that tenants in both are more likely to live on a low income and/or be in vulnerable circumstances than owner occupiers (MHCLG, 2019).

The following sub-sections give a brief overview of the provisions of each scheme.

\section{Energy Company Obligation (ECO) - Great Britain wide}

The current ECO3 programme is now entirely focussed on low income, vulnerable and fuel poor households. By contrast, previous supplier obligation programmes included incentive schemes for 'able to pay' households. Fuel companies have to meet at least $75 \%$ of their obligated targets by providing energy efficiency measures to households in receipt of certain means tested benefits (BEIS, 2018a).

Suppliers can now meet up to $25 \%$ of their targets through a local flexibility element whereby local authorities taking part in the scheme can make referrals to suppliers. The UK government established this element to help make sure ECO reached more vulnerable households and those missing out under standard ECO eligibility rules. Councils are encouraged to refer people in need but not meeting standard ECO eligibility criteria, in particular:

- $\quad$ those not claiming the benefits to which they are entitled;

- those with a chronic health condition exacerbated by living in a cold home; and lor

- $\quad$ people who frequently visit GPs or A\&E departments.

The government felt councils would be more effective than fuel companies at reaching vulnerable and other 'hard to reach' households (BEIS, 2019). Councils are encouraged to work with other local statutory and voluntary agencies in making referrals for ECO help.

Despite this focus on fuel poverty and the attempt to improve outreach through local flex, many organisations argue that ECO in its current form is not an adequate mechanism to tackle fuel poverty (Citizens Advice, 2019; NEA, 2019; Snell et al, 2018). In particular: 
- It does not provide the funding required to meet the fuel poverty target in England.

- The supplier delivery approach is mismatched to the aim of delivering fuel poverty support.

The UK government has progressively reduced the size of the scheme since 2010. In 2010, funding for the three predecessor schemes (CERT, CESP and Warm Front) totalled $£ 1.57 \mathrm{bn}$ per annum. CERT and CESP, like ECO, were funded through a supplier levy, while Warm Front was funded by the Exchequer. However, funding for Warm Front was substantially reduced in 2010 and then cut altogether in 2013. At the same time, ECO replaced all these schemes with an estimated budegt of $£ 1.12 \mathrm{bn}$ per annum. This has since been reduced to around £0.64bn per annum (Citizens Advice, 2019).

Many issues arise from the design of ECO which encourages suppliers to deliver energy efficiency measures at the lowest possible cost. For example: Citizens Advice identified the following issues:

- A volatile market: Over the course of ECO2, brokerage prices ranged from $7 p$ to $24 p$ for the same unit of work. ${ }^{12}$ The National Audit Office noted this could increase the costs of meeting the fuel poverty target in England and/or reduce the chance of meeting the target and interim milestones.

- Suppliers want a wide pool of eligible households to target to limit the cost of searching for households. This often means the most vulnerable and hardest to reach get overlooked.

- $\quad$ Even suppliers eligible for ECO are not guaranteed support; with suppliers able to choose which customers receive what type of support in order to meet their targets cost effectively.

- Suppliers can either refuse measures on the basis of value for money or ask clients for a financial contribution, regardless of individual circumstances.

- Suppliers are more likely to deliver to households who are easiest to engage, where the installation is simple and there is no additional maintenance required. There is also no incentive for suppliers to make sure ECO is integrated with complementary programmes such as home maintenance grants or social support.

- A Citizens Advice survey of local offices found that over half of advisers who had helped clients with ECO had experienced problems. Of these, $41 \%$ said that clients had found the application process too complicated, while $11 \%$ reported that clients' applications had been rejected.

(Citizens Advice, 2019)

Further delivery issues were identified by research into access energy efficiency measures:

- Energy advisors are often limited to recommending centrally defined, inflexible measures, rather than measures best suited to the property and household living there.

${ }^{12}$ ECO2 brokerage data is available at: https://www.gov.uk/government/publications/energy-companiesobligation-eco-brokerage-results 
- Disabled people and low income families often live in the poorest quality housing and have additional needs that require support throughout the retrofit process which adds expense. These households are therefore often side-lined.

- Suppliers rely heavily on referral partners, 'lead generators' or broad marketing strategies which rely on households to contact them or their agents. Many disabled and low income families miss out as a result.

- There is no single, strong and consistent approach to engaging households in England, trusted intermediaries find it difficult to refer households into schemes and as a result it is harder to support vulnerable households.

(Snell et al, 2018)

\section{England}

All social housing in England is expected to meet the Decent Homes Standard which includes provisions for efficient heating and insulation. However, over half a million homes still do not meet the standard, with quarter of a million deemed to have a Category 1 hazard (typically because they are classified as 'dangerously cold') (MHCLG, 2018).

All private rented housing in England and Wales is now expected by law to meet an EPC E standard, unless given exemption, e.g. should the cost of meeting the standard exceed $£ 3,500$ (BEIS, 2018b).

The UK government's Clean Growth Strategy (HM Government, 2017) has set the following targets:

- $\quad$ All fuel poor homes improved to EPC C by 2030, as already set out in its 2015 Fuel Poverty Strategy.

- An aspiration for as many homes as possible to be EPC C by 2035 where practical, cost-effective and affordable.

- A long term trajectory to improve privately rented homes to EPC C by 2030 where practical, cost-effective and affordable.

- Consultation on how social housing can meet similar standards over this period.

These are laudable targets. However, they are only aspirational. There is considerable evidence that current programmes are not sufficient to meet them (see, for example, the report of the Committee on Fuel Poverty, 2018 with respect to the fuel poverty target and milestones).

\section{Wales}

The Welsh Government's Nest scheme ${ }^{13}$ provides grants for free energy efficiency measures, such as insulation, boilers or central heating, to people on certain meanstested benefits in privately owned or rented homes rated EPC E, F or G. The Welsh Government has also set a requirement for all social housing to meet the Welsh Housing Quality Standard by 2020 (Welsh Government, 2008). This includes a requirement to make sure housing is adequately heated, fuel efficient and wellinsulated.

\footnotetext{
${ }^{13}$ More information at: https://gweddill.gov.wales/topics/environmentcountryside/energy/efficiency/warmhomes/?lang=en
} 
Certain deprived areas in Wales have also benefited from the Welsh Government's Arbed scheme. ${ }^{14}$ This is an area based scheme in which all housing in the defined areas is improved free of charge to minimum energy standards. Over 12,000 homes have been improved to date through this scheme with a further 6,000 improvements due for completion by 2021.

The Welsh Government encourages social housing providers and the managing agents of Nest and Arbed to integrate their schemes with ECO to maximise the number of beneficiaries.

\section{Scotland}

The Scottish Government's Home Energy Efficiency Programme Scotland (HEEPS) scheme ${ }^{15}$ includes 3 strands, two of which target low income and vulnerable households:

- $\quad$ Area-based schemes are run by local authorities, with funding from the Scottish Government and ECO, and are designed to improve energy efficiency measures to properties in certain deprived areas.

- Warmer Homes Scotland provides grants for free energy efficiency measures to people on certain means-tested benefits in privately owned or rented homes.

The Scottish Government's Energy Efficiency Standards for Social Housing requires all social housing to be improved to certain minimum energy efficiency standards by 2020. The Scottish Government is currently consulting upon an 'Energy Efficient Scotland' strategy (Scottish Government, 2018). This has set targets that all homes should be improved to at least EPC C by 2040, all private rented homes to EPC C by 2030 and 'a challenging and aspirational target to maximise the number of social rented homes meeting an EPC B standard by 2032 ' (ibid).

The Scottish Government also encourages social housing providers, local authorities and other delivery agencies to integrate their programmes with ECO to maximise the number of beneficiaries.

\section{Implications of energy efficiency legislation and regulation for energy advice}

In practice, advice on energy efficiency improvements is generally targeted at owner occupiers and private tenants, although households in all tenures can benefit from simple behavioural messages (how to use energy efficiently and cost effectively). Energy advisers can advise social tenants on how to put pressure on their landlords if they don't meet the regulated standards outlined above. However, in general social landlords perform reasonably well on meeting the standards. This is much less likely to be the case for the private rented sector, despite the minimal requirements of the regulations. Furthermore, private tenants are often reluctant to request improvements with many fearing eviction should they do so (Ambrose et al, 2017).

However, the setting of legal and regulatory energy efficiency standards does demonstrate an important point, namely their role in reducing the need for households to seek energy efficiency advice in the first place. Households living in homes meeting high energy standards should find it easier to afford their energy bills, although many may still struggle because of low incomes. In such cases, income maximisation, employment rights advice (with respect to the minimum wage and

\footnotetext{
${ }^{14}$ More information at: https://gweddill.gov.wales/topics/environmentcountryside/energy/efficiency/warmhomes/?lang=en

${ }^{15}$ More information at: https://www.gov.scot/policies/home-energy-and-fuel-poverty/energy-saving-homeimprovements/
} 
similar provisions) and switching advice becomes more important than energy efficiency advice.

The one area where energy efficiency advice may still be required for people in homes with high energy standards is on quality issues. Poor quality installation of energy efficiency measures can have damaging knock-on effects for residents. The Grenfell House fire represents the most extreme example of this. Elsewhere, poor quality installation of cavity wall insulation has caused problems, particularly damp, for a significant (but unknown) number of households. The cost of removing cavity wall insulation is far greater than the cost of installing it.

The UK government is encouraging energy efficiency installers to adopt a new quality mark to improve consumer confidence in the standard of installation under the Each Home Counts report and subsequent follow-up work (Bonfield, 2016). However, the introduction of the new quality Trust mark has been considerably delayed (BEIS Committee, 2019). 


\section{Findings from the Citizens Panels}

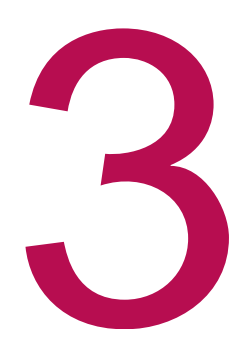

\subsection{Approach}

In January 2017 the research team began a process of engagement to identify energy users to participate in a virtual citizens panel comprised of those who selfidentify as facing a range of vulnerabilities and who experience individual, situational and/or market or structural barriers to engaging with energy advice ${ }^{16}$ and energy service providers. Any project setting out to engage such individuals will have to work very hard and employ innovative strategies to enlist respondents. On the basis of previous experience, the project team applied a range of different approaches to identify and recruit respondents, including working through trusted gatekeeper organisations and using adapted 'snowballing' techniques (where one respondent recommends another to speak to). The latter have been advocated as an effective means of recruiting hard to reach groups in health research (Sadler et al, 2010).

As an initial step, researchers employed the long-standing technique of 'hanging around' in a city centre shopping precinct in Bristol. This is something increasingly recognised as a valid technique allied to ethnographic research (Boddy, 2011; Pfaelzer, 2010). We timed the visits to coincide with an advice fair running at the centre, which would allow us to signpost participants to sources of support. We approached individuals in public areas and using short screening questionnaire, designed to determine whether they were likely to face significant barriers to accessing appropriate energy advice and support. Those identified as such were invited to take part in a short interview in a private space in a vacant shop unit. Ten individuals were recruited through this approach and each took part in semistructured qualitative interviews lasting up to 40 minutes.

In order to ensure a diverse sample of hard to reach energy users, and to ensure that we were capturing the perspectives of some of the hardest to reach energy users, other recruitment strategies were employed. Some of the most fruitful approaches involved working through organisations (with which we had established relationships) providing essential services that people in desperate circumstances will often have to engage with. They included food banks, homeless shelters and projects which prepare the formerly homeless and prison leavers for the transition to their own accommodation. Individuals recruited through these routes made up the remainder of the sample.

\footnotetext{
${ }^{16}$ This encompasses the 'looser' definition of energy advice, as described in the introduction to this report, for example it includes information and assistance provided by energy suppliers.
} 
Interviews were typically conducted on the premises of the services that had supported the recruitment of participants or in a neutral space such as a café, in line with the participants' preferences. Every effort was made to ensure that the exchange between participant and researcher was as private as possible. Interviews were audio-recorded to enable accurate analysis, where participants consented to this. All interviews were conducted either in Bristol or Sheffield where the research team had the relevant connections to recruit participants.

Due to the inherent challenges of conducting research with hard to reach individuals, we always anticipated that the study would generate a relatively small sample size. This proved to be the case with 26 interviews undertaken in total. This small sampled allowed multiple manual analysis by members of the research team which. This involved team members each reading through the 26 interview transcripts separately and inductively identifying themes relevant to the focus and aims of the study. They also highlighted specific passages and quotes to illustrate the themes identified. The research team then collectively compared individual analyses and on this basis agreed the key themes supported by the data gathered. The remaining sections of this chapter set out key findings.

\subsection{Who did we speak to?}

The techniques used to recruit participants meant that it was not possible to purposively sample citizens' panel participants. However, the resulting sample represented a good mix in terms of gender and age but less so in relation to ethnicity (18 of the 26 participants were White British). More females participated than males (15 females and 11 males) and the 40-50 $(n=7)$ and 50-60 ( $n=7)$ age groups had greater representation than other age groups. However, we did secure 5 participants in the 60+ age group and 4 in the 30-40 age group. Only one participant was aged between 20 and 30 and only one was over 80 . In terms of tenure, 15 participants were in social rented accommodation of various sorts and the remaining 11 were privately renting.

Each participant identified multiple vulnerabilities that they felt affected them - the most common of which were related to low income, mental health, physical health and social isolation (see Table 3.1). 
Table 3.1: Vulnerabilities identified by citizens panel participants

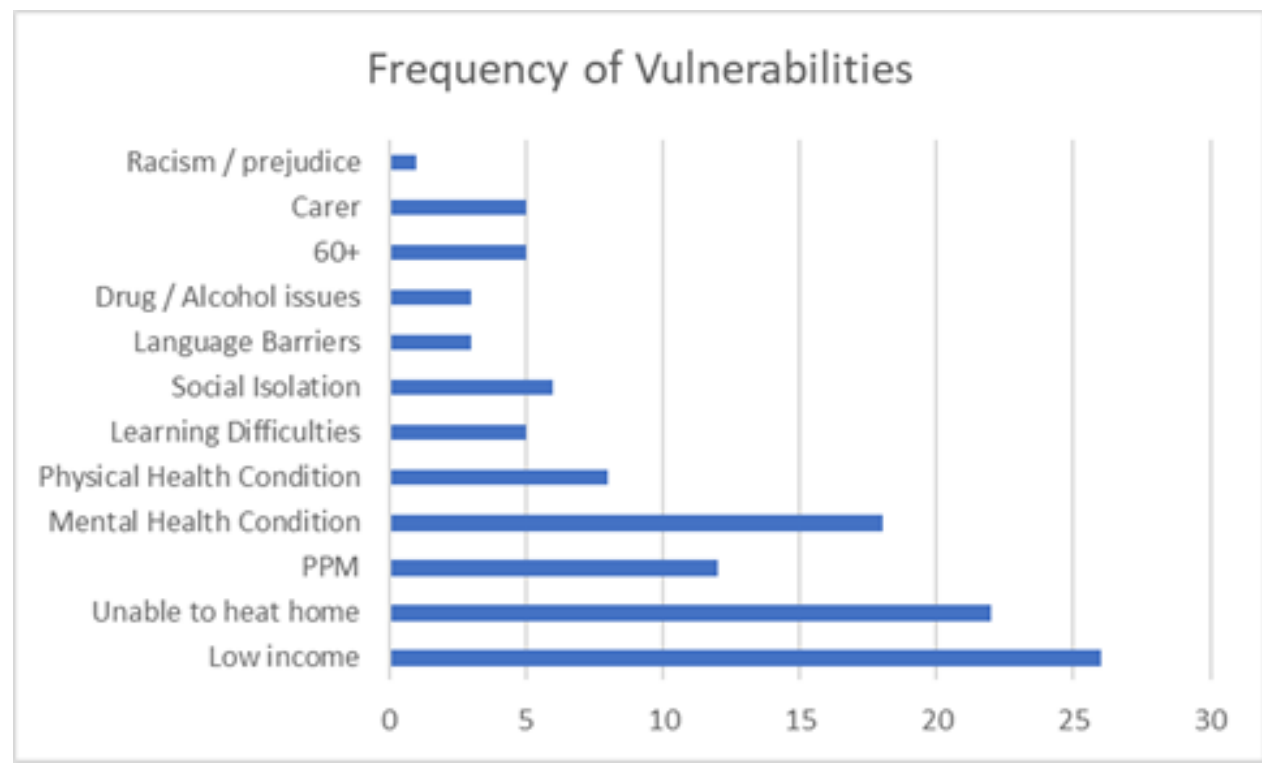

We did not specifically enquire about income levels but we did ask participants about their employment status. More than a third of the sample $(n=9)$ identified themselves as long term sick or disabled, a further 7 as unemployed (seeking or not seeking employment), 5 as retired and only 2 as employed.

Each participant was asked about what, if anything, about them or their circumstances might make them hard to reach with energy advice and support. Those who answered the question reported a wide range of issues with the majority of respondents reporting several intersecting issues. Figure 3.1 presents a word cloud highlighting the huge breadth of issues and circumstances experienced by participants, all of which undoubtedly present challenges in terms of their engagement with advice and support.

Figure 3.1: Issues identified by participants that they felt made them vulnerable and formed barriers to them accessing energy advice

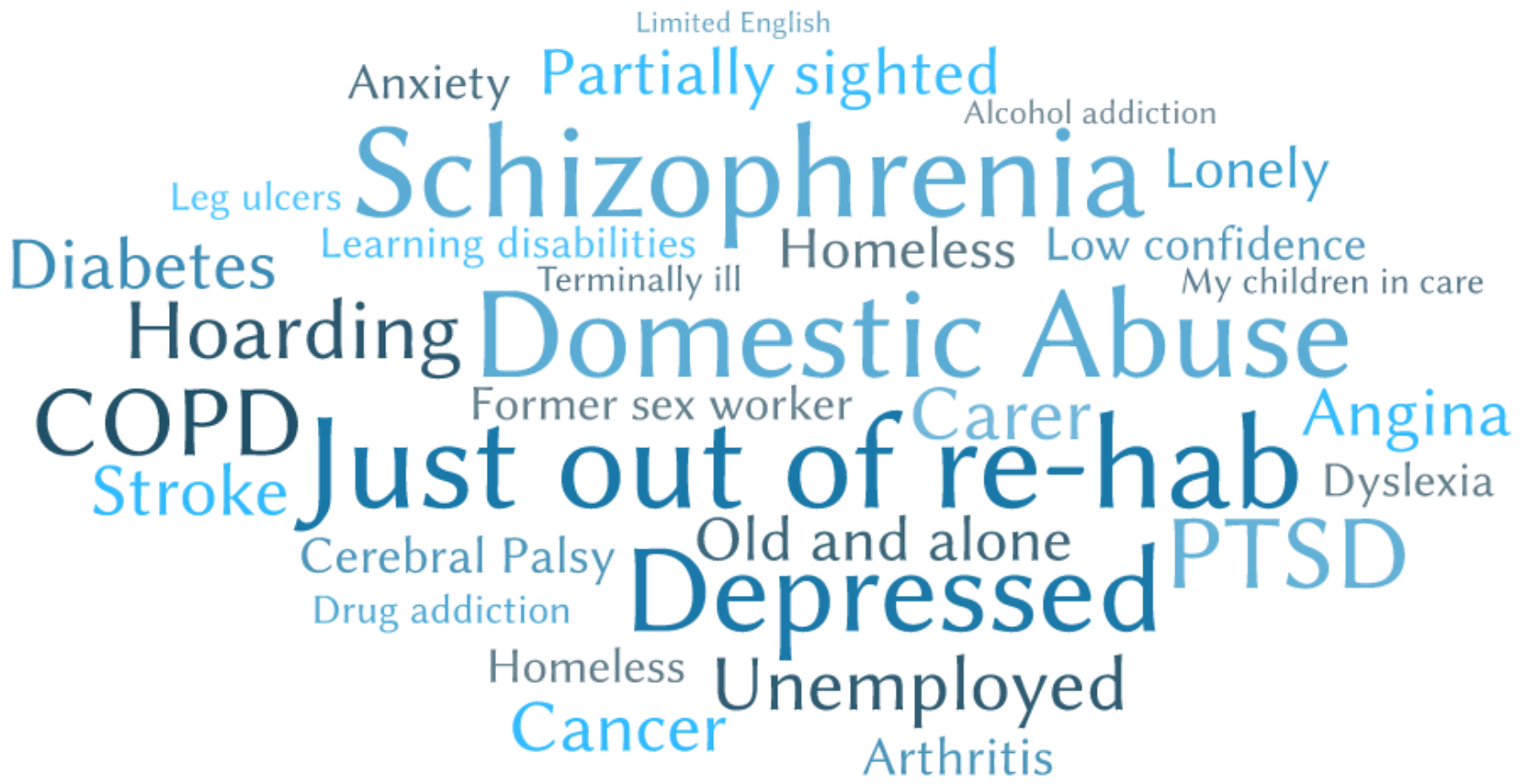


Some of the issues identified are commonly associated with hard to reach and vulnerable groups (such as depression, anxiety and various chronic physical conditions) but others are more nuanced and rarely mentioned in this context. These included: being a sex worker, - something that the participant felt had resulted in a raft of physical and mental health issues as well as forms of social exclusion. Another example was having children in care, - a situation linked to that respondent's drug addiction and chaotic lifestyle and which meant that she has withdrawn from mainstream society. Keeping warm and paying bills did not register on her list of priorities.

These example align well with Energy UK's (2019) useful categorisation of the types of vulnerability that can affect energy users. These cover financial, health and capacity related and location based vulnerabilities. In reality vulnerability usually involves a mixture of these. Indeed, those who were likely to be both financially vulnerable due to being dependent on welfare and vulnerable in terms of health and capacity made up the majority of the sample. However, as a result of the research being restricted to an urban context due to budgetary constraints, those facing location related vulnerabilities were underrepresented. Therefore they should represent a priority for future research in this area. On the other, we did speak to several participants who were reliant on district heating systems, and hence have gained some insight into this particular aspect of location based vulnerability.

\subsection{The nature of the energy related problems experienced}

Respondents were asked to describe any energy related issues they were experiencing or could remember experiencing in the past. All of those we spoke to were (at the time of interview) experiencing significant energy related difficulties. This is particularly striking given that respondents were not recruited on the basis of their energy problems.

\subsubsection{Energy affordability}

The majority of the problems reported by participants related to the affordability of energy and the difficulties they were having meeting energy costs. In the majority of cases those who reported issues around energy affordability also said they found their homes cold and difficult to heat. Of the 26 respondents, 15 reported that they were unable to afford to adequately heat their homes. As a result of these difficulties, 10 respondents reported owing money to their energy supplier and 9 were rationing their use of heat and energy or self-disconnecting and employing strategies to reduce their energy use such as spending more time outside of the home or at the homes of friends and family; wearing outdoor clothing when inside; sitting under blankets when at home and only heating one room.

"I lost a lot of money moving over from Disability Living Allowance to Personal Independence Payment. I ride around on the bus to keep warm and keep costs down. I put blankets around me and I only use the heating to take the chill off and then I turn it off. I'm using food banks to help me manage and paying £3 per week to gas and £8 for electricity but I'm worried that it won't cover the heating costs over the winter." (Norman, 67 living social housing)

Several respondents reported that they were paying off the energy debts of previous tenants and that this was contributing to their inability to afford to adequately heat their homes. This then resulted in them rationing their energy use. Those who had raised this with their energy suppliers reported difficulties resolving the issue. This aspect is explored in further detail in the next section on experiences of seeking advice. 
Caroline's story: Caroline is 41 and lives alone. She has a history of drug and alcohol addiction and anxiety. On moving into her new flat, she discovered she was repaying the previous tenant's debt. At each top up, her meter was taking $26 p$ towards the old debt. Despite having a lot to contend with in her daily life, Caroline tried initially to have the meter reset to wipe the previous tenant's debt. On contacting the energy provider, she was left feeling confused and frustrated. (Caroline, 41, living in social housing)

\subsubsection{Multiple problems}

Another widely reported issue allied to energy affordability concerned respondents struggling to understand their energy bills, tariffs and meter readings. Several also commented that they felt that their heating was out of their control.

Often, participants were experiencing several issues in tandem. For example several reported not only problems with cold homes, energy debt, under-heating their homes and struggling to understand bills, tariffs and meter readings but also a lack of confidence or capacity to seek help with these problems. It was clear in many cases that the affordability problems reflected wider difficulties associated with a low income. Thus several respondents also made reference to difficulties in affording food (and making use of food banks), and in covering other essential expenditure.

Moreover, some respondents reported additional financial challenges associated with health conditions such as needing to keep their home warm to avoid exacerbating respiratory problems or because they are often sedentary; and the cost of travelling back and forth to hospital or to support groups. These additional costs add to an already complex financial picture, as Sosha's story highlights:

Sosha lives in a flat with her daughter aged 2 who is asthmatic. The flat is difficult to heat and Sosha spends time at her parents as much as possible in order to keep warm. She is afraid to use the heating as it is expensive but knows that her daughter's asthma is exacerbated by the cold. Sosha spends about £35 per week on heating "let's say I top it up in the morning with £5, the next morning I definitely have to put on another £5". Since losing her job, Sosha is using more heating as a result of spending more time at home and is going into emergency credit on her pre-payment card even though she tries to keep the card topped up.

\subsubsection{Tenancy issues}

It is also worth noting that many participants raised energy problems that were linked in some way to their landlord. Primarily being a tenant caused problems when it came to trying to resolve energy problems (as discussed in 3.4 below) but in some cases, private landlords were identified by respondents as causing or frustrating their energy problems. For example, in one case stalemate had been reached over a meter reading because the energy provider was unwilling to take a reading until a light was fitted in the basement area where the meters were housed, but this area was controlled by the private landlord. The respondent felt unable to pursue the issue with his landlord and continued to receive estimated bills that he felt do not reflect his usage. These kinds of situations were not exclusive to the private rented sector. This is reflected in two reports of social housing tenants who reported struggling with inefficient or ineffective district heating systems and/or poorly insulated homes. Peter's story provides an example of this:

Peter suffers from depression and anxiety, is learning disabled and socially isolated. He finds his heating ineffective and it doesn't keep his studio flat adequately warm. He rents his flat from a social landlord and pays a flat rate for 
his heating as he is on a district heating system. This means he can have the heating on all the time but the flat remains cold. Peter spends time outside his flat to keep warm and when inside he uses hot drinks to keep warm and often finds it too cold to sleep. He feels the heating is outside his control and doesn't know where to turn. (Peter, 53, living in social housing)

Peter has also experienced problems with his electricity supplier. He had spent some time away from home caring for his mother in another city but had maintained his tenancy throughout. He returned to find that a pre-payment meter had been installed in his flat without his knowledge. When he contacted his energy supplier about this they told him they thought the flat was vacant. He is still trying to get the meter removed.

\subsection{Experiences of seeking help and support}

A primary aim of the interviews was to elicit the energy problems that participants may have experienced. As outlined in Chapter 2, consumers generally do not consider energy advice a priority, except in a crisis such as a boiler breaking down or an unexpectedly high fuel bill. At the same time, energy issues may be picked up as part of a package of support put together in response such a crisis. Therefore the expectation was that many participants would not have sought help with the energy problems they described.

Contrary to this received wisdom, it emerged from the interviews that in fact 17 of the 26 respondents had sought help explicitly in relation to the energy problems they were experiencing (as opposed to advice about another matter that picked up on energy issues). Of those, 12 had contacted their supplier directly and five had approached Citizens Advice or another independent advice provider.

Most of these respondents had approached their energy supplier in response to a communication they had received or because they perceived that it was the only way to resolve their problem. All of those who had sought advice through Citizens Advice or similar reported positive experiences but only four of those who approached their energy supplier reported the same outcome. The nine respondents who had not sought help from anywhere said that, despite wanting help with the problems they were experiencing, they felt overwhelmed by the prospect or didn't know where to turn. However, many acknowledged that their energy issues were crowded out by other complex problems that they were facing and was therefore relatively low on their list of priorities.

\subsubsection{Trust}

We asked those who had sought help to provide more details about their experiences. In line with the findings of the CCVC, many of those who had approached their energy supplier reported poor and inconsistent treatment. It was also apparent in participants' accounts that they do not trust energy suppliers, and therefore their expectation is to be treated poorly and 'fobbed off', as several participants described it. This issue of lack of trust in the sector is also picked up by the CCVC in its report.

Valerie's experience provides a good example of these issues. She is 80 years old, lives alone and is in the early stages of dementia. She contacted her energy supplier when she realised that she was several hundreds of pounds in credit on her energy account and needed to use that money for other things. She felt that the energy supplier in question was reluctant to reimburse her and in the end grew so upset by the way she was treated that she asked her son to intervene. 
"They thought oh she's just an old lady on her own and they kept trying to dodge the issue".

"I think they were fobbing me off and were trying to say I didn't understand the system... If I do have to ring any of these companies I usually ask who I am speaking to although you have got no knowledge if they are giving you a real name. But why do I bother because the chances of you being able to speak to Hannah or so and so are remote so you are always have to explain the whole thing over again from the beginning". (Valerie, 80, living in private rented housing)

\subsubsection{Multiple contacts}

Valerie was particularly disenchanted by the fact that she would have to explain her situation from the beginning every time she made contact with her energy supplier and found it exhausting. This was a commonly identified problem and led three respondents to comment that the experience had left them feeling unwell. One respondent, Anna (a Polish migrant worker with limited English) commented that she was promised call backs on several occasions but they never materialised. Such broken promises damaged the trust between her and her energy supplier.

Valerie was also convinced during her exchange with her energy supplier to take a smart meter on the basis that this would enable a more accurate picture of her energy use. However, she did not understand it or trust that it would provide the stated benefits. She felt uncomfortable in a world that is 'geared to the young and increasingly reliant on technological solutions. In essence, Valerie felt that there was no sensitivity to her individual circumstances and preferences when she made contact with her energy supplier and as a result she perceived them as almost inhuman:

"I don't like the lack of connection, you just feel as if everything is being done by robots. I think what is really unfair is the way that communications are working with everybody all geared to the young and new technology. I think they should keep the options open so that it's not just a digital world... I think it's being pushed at the expense of people who can't access it easily and I think that is really bad. They are anonymous, they are not real."

\subsubsection{Understanding consumer' circumstances}

Similar experiences were reported by other respondents who felt that their circumstances were ignored. For example, despite being registered as blind, such as Christine (53) had been repeatedly asked to go into her cellar to read the meter. Others reported conversations being 'hijacked' by the energy supplier to pursue another agenda. Caroline had a similar experience. She is disabled and has a chaotic life. She called her energy supplier as she was desperate to get her prepayment meter reset to avoid paying a previous tenant's debt, but soon found herself in a confusing conversation about energy tariffs:

"He told me this tariff, I don't even know what they were on about, he was coming out with these figures, to me it's no good talking about figures I haven't got a clue and like an idiot I am going yeah yeah yeah that's alright. I said that just to get him off the phone. It's not simple to get them to come and do one thing, its 101 questions. It stresses me out. It's stressing me out just thinking about it right now"

She has now resolved to pay the previous tenant's debt to avoid contact with her energy supplier. She has little awareness of any alternative sources of advice. 
Alisdair (53 and long term sick) provides a further example of someone who has psyched himself up to contacting his energy supplier but failed to find a solution. Consequently he continues to tolerate the problem to the detriment of his mental health. He was aware of alternative sources of advice but finds accessing them too stressful. Alisdair's situation is explained in this excerpt from the researcher's field notes:

"He has contacted the energy supplier on several occasions, and wrote letters but has not been able to resolve the issue. He has approached CA but the queue was long so he walked away as it was too stressful. He feels unable to deal with the situation as there appears to be no solution. The energy company doesn't want to listen or acknowledge that he is a new tenant. He is therefore still liable for the £2111 debt. The issue is negatively affecting his mental health and he is obsessively monitoring his energy use on an hourly basis. He worries that if he makes too much of a fuss that the energy company will say he actually owes more money. 'Better the devil you know', he says."

\subsubsection{Negative feedback loops}

There was also ample evidence of 'negative feedback loops' in relation to exchanges between participants and energy suppliers. Participants reported that they would often enter into the conversation in an anxious state because of the situation they were seeking help with; because they anticipated problems and/or because making the call pushed the limits of their confidence. This anxiety would then frequently lead to heated exchanges or be interpreted by the person taking the call as hostility or abuse. As a result, on some occasions the call was terminated before a solution was found. A further call then either does not happen at all or provokes even greater levels of anxiety. Sophie provided an account of this type of experience and how it made her feel:

"I have a panic attack when I pick up the phone to talk to them. Half the time, when you're getting het up you are trying to explain to them something and they are not understanding for one reason or another and then you get mad because of it and they put down the phone." (Sophie, 41, disabled, living in social housing)

\subsubsection{Poor understanding}

Feeling poorly understood and not listened to were identified as problems by several other respondents including Saagal who came to the UK as a refugee and struggles to communicate in English. She is highly educated and feels deeply frustrated when she is not understood. She said that when she contacted her energy supplier about high bills that she couldn't afford, she felt "intimidated and small and disrespected" and as a result has not made contact since.

Those who reported a positive experience when seeking support from their energy supplier were all seeking to reduce their monthly payments and found this a straightforward process. This perhaps reflects the fact that their request was relatively uncomplicated. One respondent who reported a good outcome said that he was treated better after he explained that he had mental health issues.

\subsubsection{Reluctance to seek help}

The nine participants who had not sought help with the energy problems they described cited a range of reasons why. These are in line with the factors identified by previous studies such as Gousy (2014). They include not wanting to be a 'nuisance' or a 'problem person'; not knowing where to start in terms of seeking advice; worrying about the cost of the call; being deterred by bad experiences in the 
past (including 'going round in circles' with push button menus); fear that making contact with an energy company in particular will 'open a can of worms' and lead to them being linked to an even greater level of debt; fear of being pressured into something such as a smart meter or because dealing with energy issues is not familiar to them, for example because it was a role that a partner fulfilled in the past.

\subsection{What would make it easier to access energy advice and support?}

At the end of the interview, participants were asked to reflect on what would make it easier for them to seek help and advice with the energy issues they had described. We asked them to think, in particular, about how they would ideally like to receive advice and from whom. Responses to this question were very clear and there was little deliberation from participants about what they want and need in terms of advice provision. There were also few discernible differences in preferences according to participants' individual circumstances.

\subsubsection{Face to face advice and support}

Of the 26 respondents, 23 said they would prefer face to face advice as the primary mode of engagement as opposed to the current system where phone and internet are the main (and often only) options. In terms of how face to face energy advice would be delivered, over half of those who advocated it felt that shops or other premises in accessible locations- in the style of local Citizens Advice bureaux- would be the best option. The rest suggested that home visits would be more effective. However, there was a clear sense that any opportunity for face to face engagement would be welcomed over and above phone or internet provision.

Face to face advice was widely felt to offer greater scope to be heard and understood, especially amongst those who struggled with communication for a variety of reasons. It was felt that complex situations could be explained more easily in a face to face encounter not least because it is easier to share documents, letters and even photographs pertaining to the problem in this setting and it's also possible to bring someone else along to provide support. It was also felt that face to face encounters offer the opportunity to assess how trustworthy and genuine the advice provider is:

"It's better that way because you know you're going to get somewhere. They can say what they want over the phone but face to face is better because then you know it's coming from the mouth and not coming from over a phone, you can actually see the person's language, you can actually see if they are being honest and truthful in what they say and do. It's not easy to do it over the phone; it's like disbelief when it's over phone...you can't see what body language it is." (Caroline, 41, disabled, living in social housing)

"If I could speak to them face to face then they could perhaps see the difficulty I was in" (Sophie, 40, disabled, living in social housing)

Those who advocated home visits felt that they would enable advice providers to reach a greater breadth of people as they remove any issues around mobility or travel; reduce anxiety as they are in a familiar setting and enable the occupant to convey the nature of the problem more easily.

A small number of respondents felt that over the phone advice would be acceptable with some modifications to the current system including the eradication of pushbutton menus; free phone numbers and fewer transfers of callers between departments requiring them to explain their situation again. 


\subsubsection{Assigned support staff}

In order to counter the need to explain their situation repeatedly to different people each time they called, several participants also expressed the desire to have a more personal service including having an assigned person to talk to who would handle their issue from start to finish. Some added that the person assigned to their case should also have the power to resolve it without lots of subsequent referrals. It was also important to participants that they were not hurried and were given time to explain their situation properly. There was also a call for the use of simple, uncomplicated language and the avoidance of jargon.

In terms of the ideal source of advice, the vast majority stated that they would prefer advice from an independent and impartial body. Several expanded on this to say that they considered voluntary and community sector (VCS) organisations best placed to deliver this. Four or five respondents had links to VCS organisations such as food banks, and homeless charities and said they would probably turn to them for support in future. Only one respondent suggested that they might turn to their social landlord for help.

Trust in energy companies was almost universally low. However, it is important to note that despite this clear preference for VCS advice, the majority of participants who had sought help with their energy problems had gone to their energy suppliers despite their lack of trust in them. Many participants talked about finding it difficult to know where to turn. This underlines their difficulty in navigating what energy advice and support is available. It is also worth noting that several participants stated that their own family was their most trusted source of support. 


\section{Stakeholder co-}

\section{production workshop: sharing findings, developing ideas}

\subsection{Persona and scenario development}

In February 2019 we held a final meeting of the SRG which was attended by 15 individual stakeholders representing Citizens Advice (National and Manchester), National Energy Action, Energy Saving Trust (Scotland), The National Institute for Health Research, the Universities of Sheffield, Salford and Sheffield Hallam, Doncaster Council. There were also two lay participants. The purpose of the event was to share some of the findings from the citizens panel research, and to work with those present to develop solutions to the problems experienced by participants. It was intended that these solutions would inform the recommendations made in this report. The ethos of the event was to co-produce recommendations with those who might be involved in promoting and implementing them in practice.

This creative co-production method was facilitated by the NIHR which has pioneered this as a means of translating knowledge into action in a health research context. To be more specific, the method began by taking personal accounts garnered through the citizens panel and turning them into pseudonymised 'personas' representing a range of hard to reach energy users (see Image 4.1 below). 
Image 4.1: Partially populated personas based on citizens panel participants
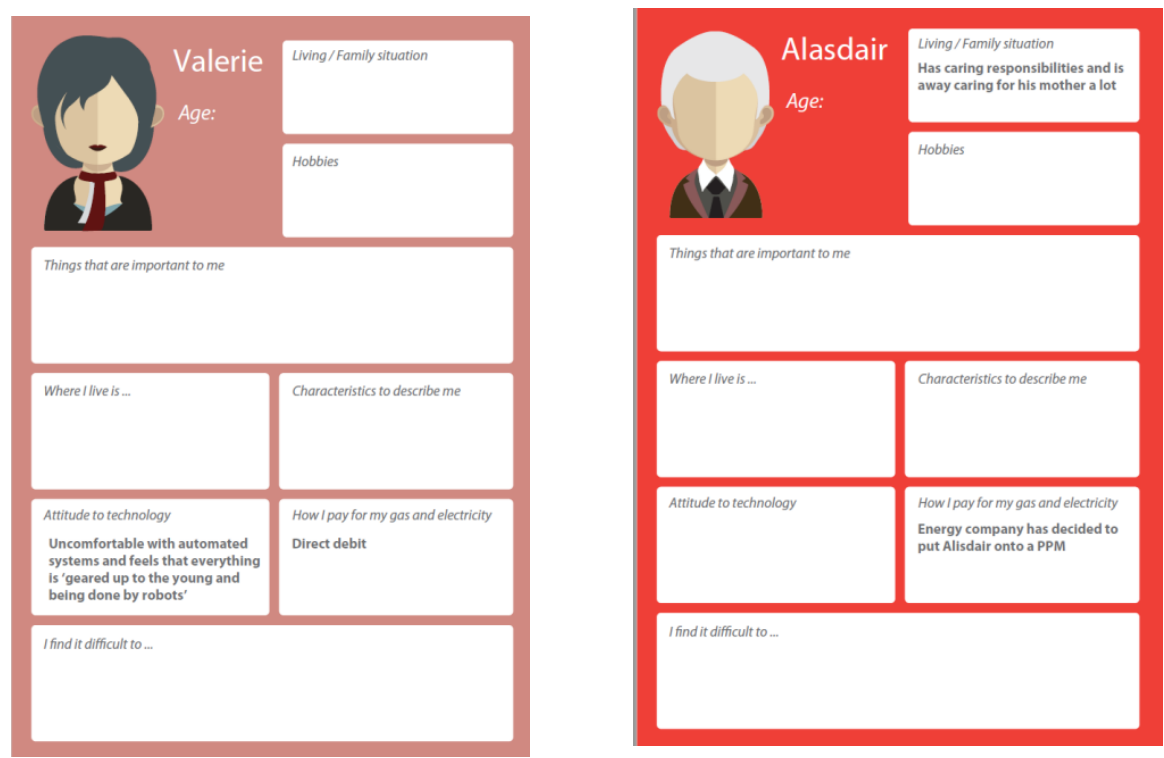

These personas were effective in bringing to life the complex circumstances of hard to reach energy users. They also conveyed how energy issues are likely to form just one problem in a host of competing pressures that participants were facing in their daily lives, and how energy problems were nearly always intermeshed with other problems such as a low income, insecure housing, insecure employment, poor physical and/or mental health, poor support networks, and /or low levels of education etc.

The stakeholders were then invited to develop the personas by adding detail to their stories based on their own experiences of hard to reach energy users. Through this process the personas became amalgams which embodied the characteristics of many different types of hard to reach consumers. Image two shows how the personas evolved through the persona development exercise.

Image 4.2: examples of fully populated personas which have now become amalgams of different hard to reach energy users
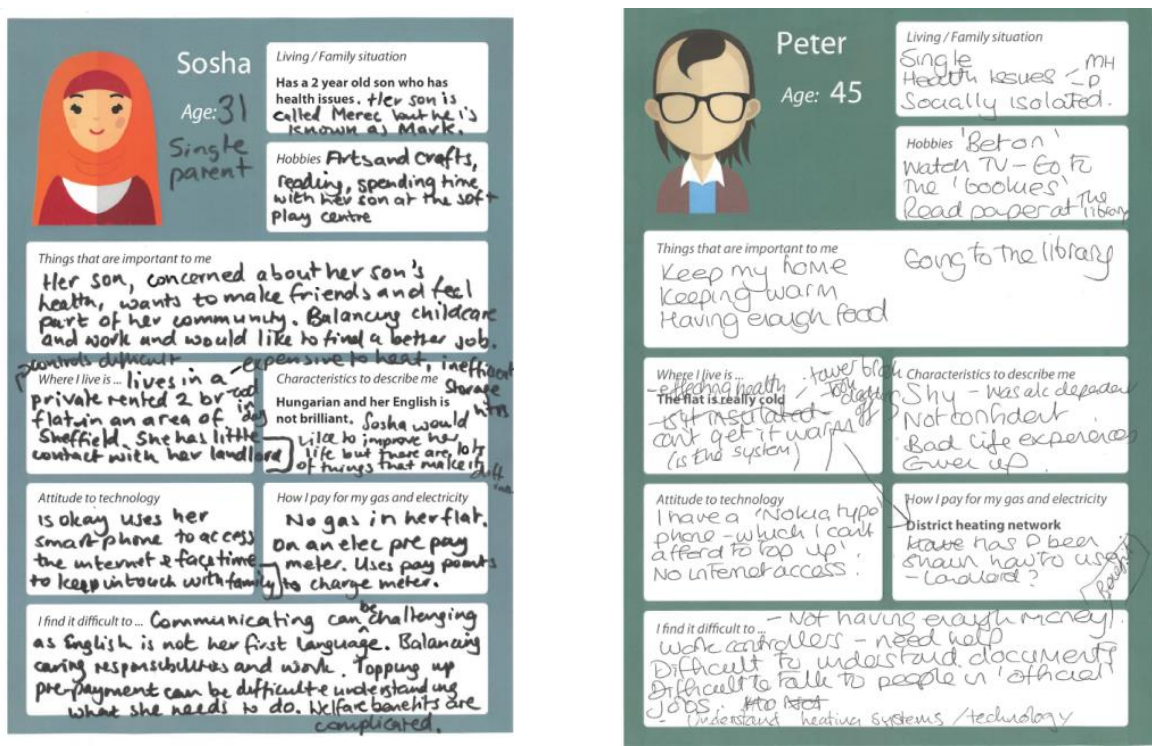

The next stage of the workshop involved break out groups examining situations described by citizens panel participants and developing them into a range of 
scenarios. Each group considered a different scenario (see Image 3 for examples) and considered the current unsatisfactory scenario described by the participant and the outcomes that might stem from it, and from this constructed a more positive scenario which involved the participant accessing high quality energy support leading to significant improvements in their situation.

Image 4.3: Example of scenarios based on data collected through the Citizens Panel
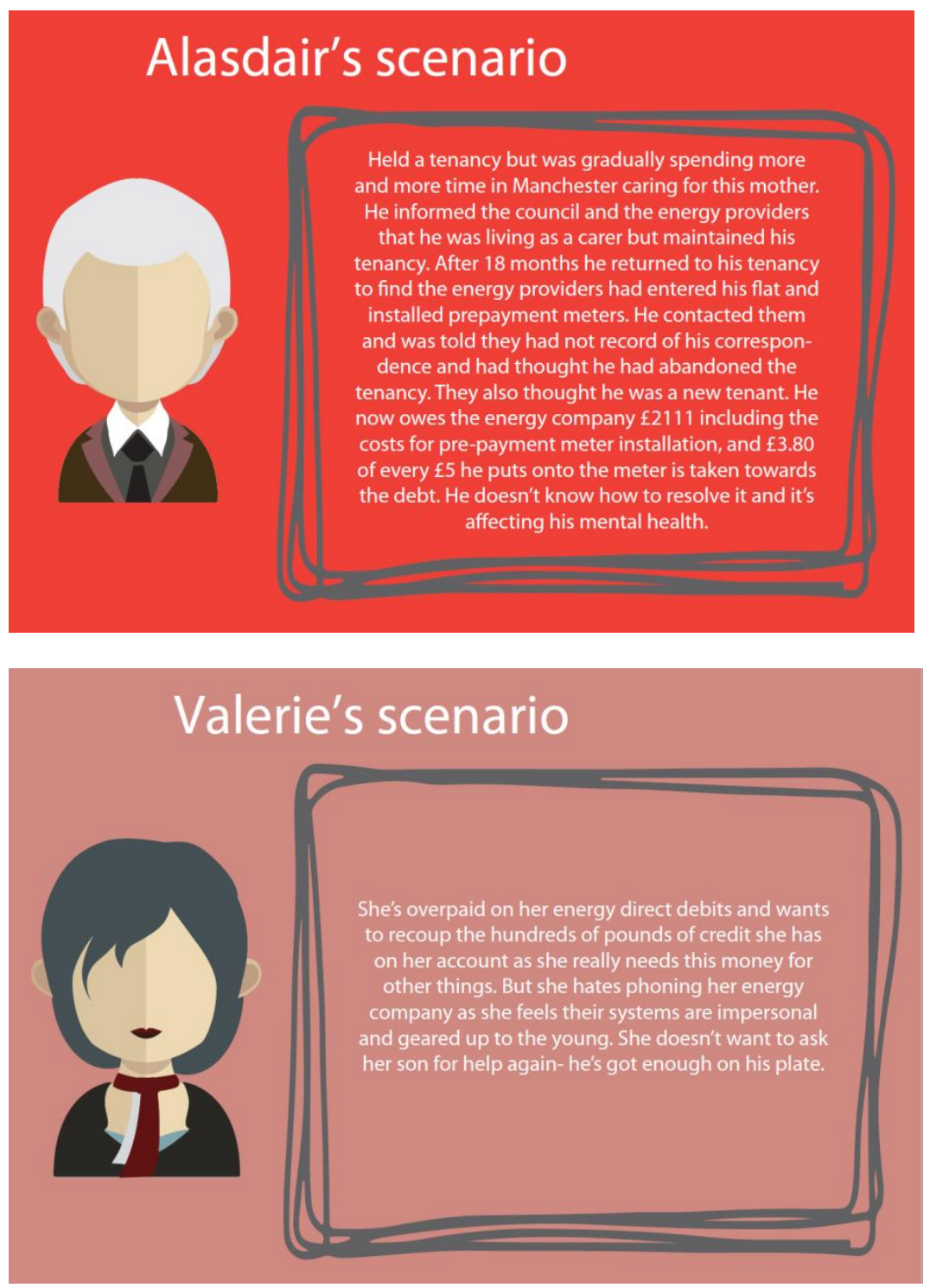

Storyboards were then used to identify the steps necessary to help the personas to reach the positive outcome. This involved creative thinking about possible solutions that go beyond current practice and/or draw on knowledge of good practice held within the stakeholder group. Simple and affordable interventions and initiatives were encouraged. The ideas generated ranged from ambitious national level campaigns to specific localised interventions. Three examples are in the following section.

\subsection{The development of solutions}

Scenario: Peter finds his home too cold to spend time in during the day. As a result, he spends a lot of time at the local library keeping warm. It makes him unhappy as he would like to spend more time at home. He is in social rented accommodation is on a district heating network and he feels his heating is out of his control. 
Solutions: Difficulties operating heating systems were regarded by some present as the fourth cause of fuel poverty, suggesting that Peter's predicament is a common one or a 'social norm'. The group felt that an effective way of engaging Peter might be through a Tenancy Support Officer who is embedded in the community and has the time and experience to engage face to face with tenants. Contact between them might be initiated through a 'social norms campaign' which, in practice, would involve a simple, attractive poster distributed to tenants stating that many people struggle with their heating and asking them to get in touch if they are experiencing any problems.

The poster would suggest that tenants call the number provided and ask for 'help with heating' to reduce anxiety around knowing what to say when making contact. Once a dialogue was established, the Tenancy Support Officer could, if Peter wished, link him into a range of relevant affordable warmth programmes with the potential to improve his circumstances. An experienced advice worker in the group emphasised the importance of respecting individuals' wishes where they are reluctant to engage whilst at the same time maintaining some unobtrusive contact to build trust and keep the option of a greater level of support open.

\section{Image 4.4: Storyboard for Peter}

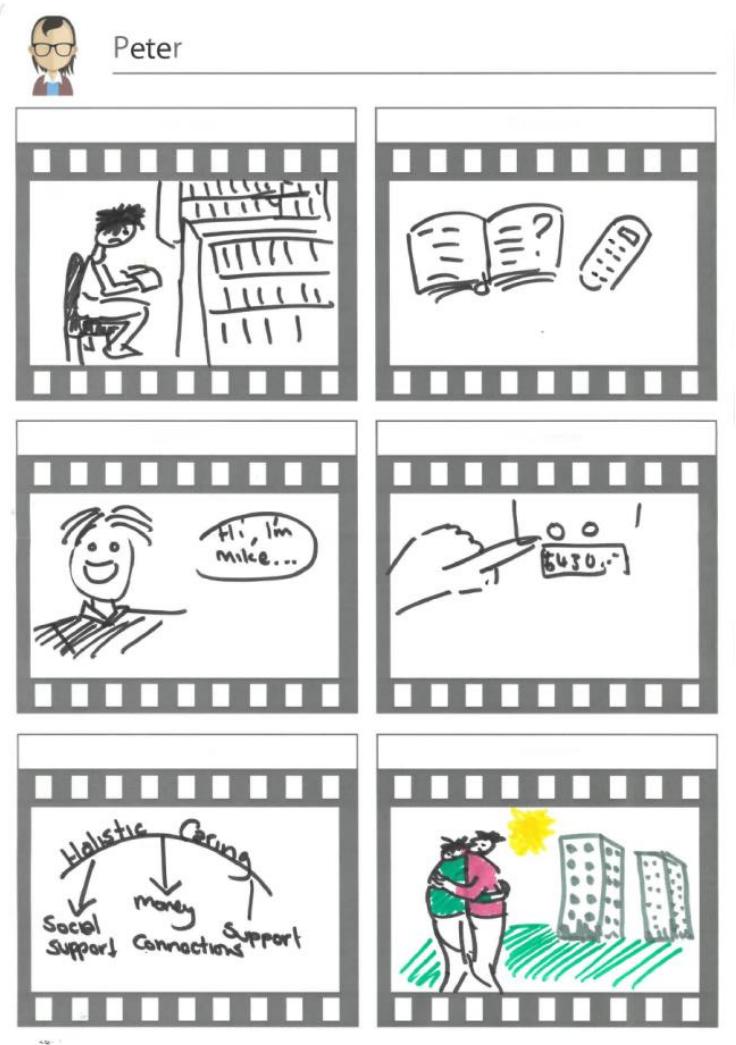

Key ideas:

- Reaching out through simple written communication and offering a form of words to unlock access to support.

- Using written communication as a springboard to face to face engagement.

- Working through knowledgeable and skilled professionals already embedded in the community.

- Maintaining gentle contact in the face of initial unwillingness in order to build trust and keep lines of communication open. 
Scenario: Sosha's son's asthma is exacerbated by living in a home that is expensive to heat. Sosha's English is limited and she relies on a friend to help her communicate with her GP about her son's health.

Solutions: In some parts of the country Citizens Advice place advice workers in GP surgeries/health centres to run regular advice clinics. It was suggested that Sosha's GP should make the connection between Sosha's struggle to keep her son's asthma under control and the difficulties she's experiencing in terms of keeping her home warm. The GP could then connect her to a Citzens Advice worker stationed within the surgery who could help her to access support through an 'income maximisation exercise'. This would ensure that Sosha is receiving all the benefits she is entitled to. The advice worker might also engage a translator through the local authority and might be able to help Sosha register for the social housing waiting list, at the same time finding a better private landlord through a local selective licensing scheme while she waits.

Some local branches of Citizens Advice provide free advice phone points in GP surgeries/health centres rather than advice clinics. This has the advantage of lower costs; moreover, some people might prefer to use a phone than arrange an appointment with an advice worker. However, the advice workers present felt that face to face engagement is often preferable for a first appointment, with further appointments provided over the phone. This initial face to face engagement helps establish a relationship of trust between the two parties.

It was acknowledged that establishing advice clinics in GP surgeries requires funding to cover the advice workers' time and costs, e.g. travel, access to mobile data (since public wi-fi is not sufficiently secure for recording client data). Most GP practices/health centres provide space free of charge for advice clinics, although some expect the advice provider to effectively rent the space.

It was also suggested that there should be local and national campaigns to raise awareness of the links between cold homes and poor health, and that such a campaign could be boosted by working with the BBC to develop a storyline on this topic for a popular soap. 


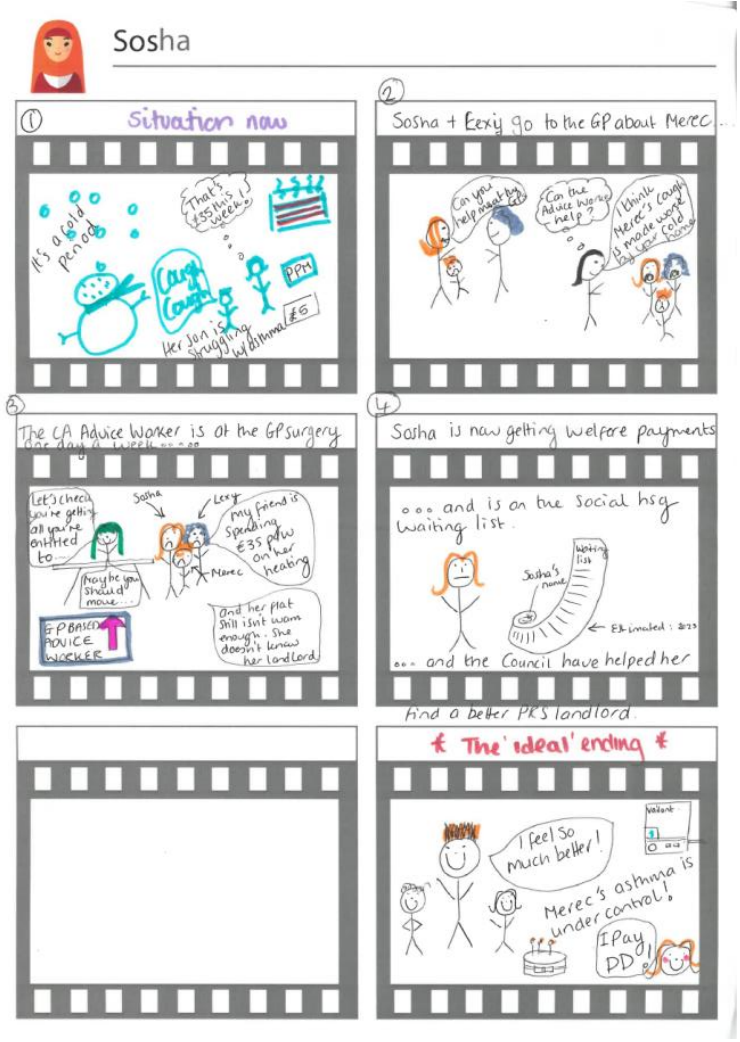

Key ideas:

- Wider roll out of advice clinics in GPs surgeries/health centres. The NHS and NICE should recognise the health and well-being benefits of providing advice clinics in primary care settings.

- $\quad$ Linking advice clinics to high footfall campaigns such as flu jab clinics, baby clinics, memory clinics, etc.

- $\quad$ Stationing free to use phones in primary care settings linked to local advice providers for people who are happy to discuss their issues by telephone.

- $\quad$ Raising awareness of local advice provision among primary health and social care workers and making it easy for them to contact the advice service (this is a key recommendation of the NICE guideline on tackling ill health associated with cold homes).

- Working with broadcasters to raise awareness of the links between cold homes and health.

Scenario: Diane is dyslexic and finds the language used by energy companies confusing. She avoids contacting them at all costs despite being on an expensive energy tariff.

Solutions: Diane is comfortable using her smart phone to access services, pay bills, particularly as it avoids having to phone service providers or companies. Therefore, the solution developed by the group involved the development of a simple and attractive website or application called My Energy Doctor, designed for people like Diane who prefer to avoid face to face meetings or over the phone communication.

The website would link to content on trusted existing websites such as Citizens Advice, Money Saving Expert and the Government's simple energy advice service. 
The website would offer support with a range of common energy problems such as difficulties with pre-payment meters, high bills, energy debt, overpayment, tariff switching or cold homes and would provide clear and frank advice on the options and help on offer. It would be smart phone and tablet compatible and would offer an 'online chat' option for more bespoke support. The website would be customised to make it easy to use for those with common difficulties such as dyslexia and impaired vision. The website could be funded by the providers of the websites it links to and by advice providers who could use it to extend their reach.

\section{Image 4.6: Diane's storyboard}

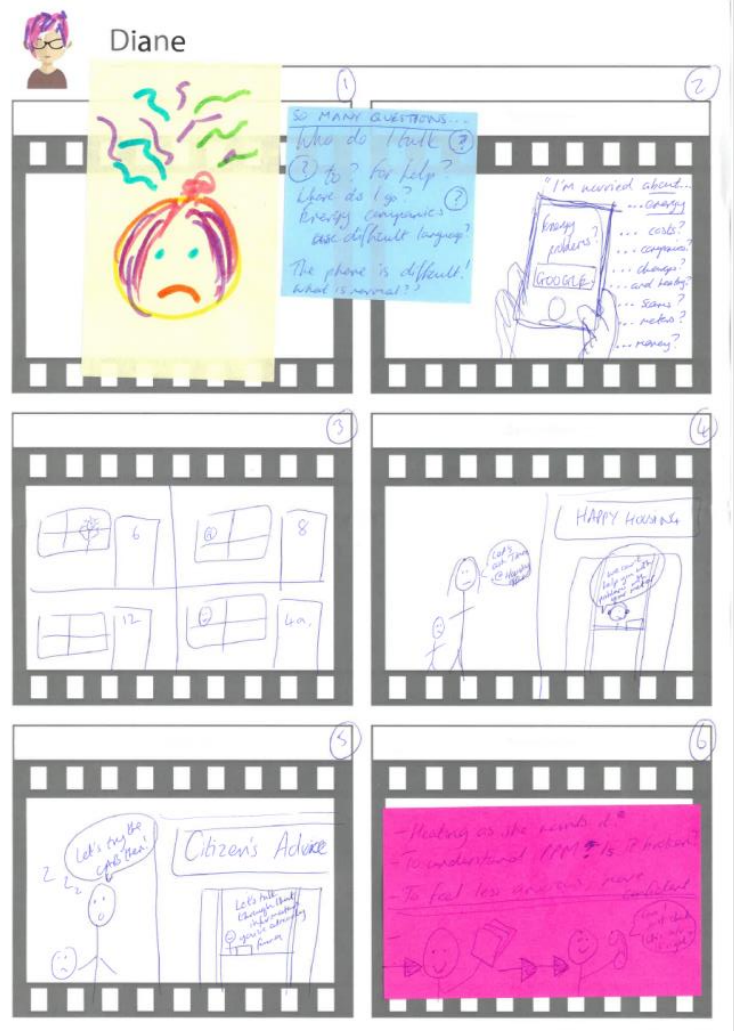

Key ideas:

- Using simple and attractive web platforms to engage those who avoid face to face and phone contact in energy advice and are comfortable accessing information on-line.

- $\quad$ Linking such platforms to trusted advice providers to boost credibility.

- $\quad$ Offering advice providers an opportunity to extend their reach through a neutral platform.

\subsection{Key learning points}

Having spent time familiarising themselves with the realities of accessing energy advice as a hard to reach consumer, the stakeholder group generated a series of recommendations which they felt should be communicated to a wider audience, as follows:

Work through professionals embedded in communities. Those aiming to engage more effectively with hard to reach energy users should consider working through or with the raft of professionals working on the ground within communities, such as health professionals (district nurses, midwives, Home from Hospital providers), 
housing officers and housing repair teams. Such professionals have tacit or explicit skills in engaging with vulnerable and marginalised individuals, and are likely to be trusted by their clients. However, it was cautioned that many fuel poverty initiatives have relied upon this approach resulting in huge pressure being placed on these professionals to succeed not only in their core roles, but also in linking their patients and tenants into other initiatives. It is important that these initiatives are supported at a strategic and if necessary, legislative or regulatory level.

- Embed support to address home energy problems into the routine management of chronic conditions and hospital discharge processes. Early access to support to address home energy issues may obviate a proportion of hospital admissions and lead to improvements in chronic conditions. This should provide an incentive for health professionals to engage with energy advice agendas.

- Work with agencies undertaking preventative work in relation to health and safety to add energy to their agendas. This would include the Fire and Rescue Service (through homes safety checks) and Public Health departments which may have resources and experience to contribute.

- Work with people's existing motivations. For example, if food and/or health are of primary importance to households with young children then energy advice initiatives should work through the relevant channels. This may involve setting up outreach clinics with GP surgeries/health centres or at foodbanks.

- Be alert to energy issues that are not perceived as such. Energy issues bound up with other problems may not be perceived as such by those experiencing them. For example: respiratory problems may not be linked to a cold home, or difficulties affording food may not always be considered in the context of high energy bills. This is why it is important to work with existing motivations.

- Use general financial concerns as a conversation starter. Following on from the previous point above, issues with debt and finance are reportedly the most common drivers of people making contact with an advice agency. Energy advice needs can often be identified and addressed through broader conversations about household finance and debt.

- Talk to everyone about potential energy issues. As it can be difficult to identify hard to reach energy users, those aiming to do so should consider 'hanging around' at key events with a wide appeal such as flu clinics, attempting to talk briefly to everyone in attendance to convey key messages or signpost to sources of support.

An important overarching point was raised in relation to the need for careful coordination when seeking to take a multi-agency approach to engaging hard to reach energy users. One agency should take the lead in ensuring that front line workers are not overburdened by efforts to serve multiple agendas. They should also ensure that all agencies engaging with hard to reach groups are aware of key initiatives that might improve the circumstances of their clients or at least place them on to the relevant referral pathways.

In this context, the Making Every Contact Count (MECC) initiative was felt to be highly relevant and there was wide agreement that its principles should be widely promoted in an energy advice context. MECC is an initiative aimed at promoting healthier lifestyles in order to reduce risk of disease amongst the general population. A statement issued by Public Health England and the NHS in 2016 indicated that the approach should be applied across all health and social care organisations and other 
relevant agencies throughout the UK. This included financial advice, housing, social care, employment, education and training and home safety agencies.

The MECC approach is outlined in Recommendation 5 of the NICE Guidelines on excess winter deaths and illness, and the health risks caused by cold homes (NICE, 2015), which set out a series of actions for health and home care professionals. The premise of MECC is that the millions of routine engagements that organisations have with their clients on a daily basis provide a previously untapped opportunity to pass on brief messages about healthier lifestyles and the importance of maintaining physical and mental wellbeing. The brevity of these exchanges is critical to the success of the initiative, as participation in MECC is not intended to place additional strain on busy professionals or to impinge on the primary purpose of the conversation (PHE, 2016).

It is notable that the solutions developed through the workshop did not yield many ideas in terms of the steps that energy suppliers should take to make their services more accessible, even though they are the first point of contact for many consumers experiencing problems. This perhaps reflects the fact that no energy suppliers took up invitations to participate in this stakeholder event. As it was, those present also lacked direct insight into what is possible within that environment. This is something we have sought to address in the final chapter of this report. 


\section{Conclusions}

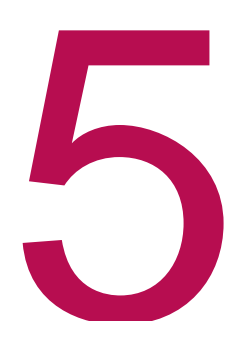

This chapter of the report aims to identify the most significant findings to emerge from this project and set out a series of recommendations for policy and practice. It draws on three main sources: the review of current thinking, policy and practice on hard to reach and vulnerable energy users (Chapter 2); the empirical research conducted with 26 hard to reach energy users through the citizens panel (Chapter 3 ); and the views of key stakeholders gathered through a series of meetings and a final workshop (Chapter 4). It also draws on expertise and experience within the project team.

\subsection{Equitable access to energy advice and services}

As noted in Chapter 2, the provision of inclusive services entails suppliers taking a proactive approach to ensuring everybody has access to positive action to address their currently unmet needs. Service providers should identify the needs of specific groups of people, while recognising that these may be subject to change given the transitory nature of vulnerability for some consumers.

Ofgem's vulnerability strategy, the inclusion of a vulnerability principle within licence conditions and implementation of the recommendations of the CCVC should all boost inclusivity in the provision of energy supply. However, the statutory provisions within the original Utility Act need updating, particularly given the many changes in the energy market that have taken place since 2000. The government and Ofgem should also encourage energy suppliers to adopt the BSI inclusion standard as a mechanism for fostering an inclusive culture. The findings of the CCVC and of this research show that energy suppliers have a long way to go and that these sorts of measures are urgently required.

Considering energy demand services, there is substantial evidence that ECO is illsuited to meeting the needs of consumers in vulnerable circumstances (Snell et al, 2018; IPPR, 2018; Citizens Advice, 2015). Commentators have described ECO as a programme that delivers a 'vanilla' product at volume for the 'low hanging fruit' (EFPC/ESRC seminar, 2018). It is debatable whether a supplier obligation programme is capable of adequately meeting the diverse needs of consumers in vulnerable circumstances on its own. Certainly, it seems to work best when delivered alongside a publicly funded programme that has explicit inclusivity objectives and targets, as is currently the case in Scotland and Wales (Snell et al, 2018).

Irrespective of potential future reforms to energy efficiency policy, such as the establishment of a publicly funded energy efficiency programme in England, it is clear that the ECO programme needs to become more sensitive to the needs of consumers in vulnerable circumstances. It is disappointing that the CCVC did not investigate suppliers' delivery of ECO, despite ECO being explicitly intended for consumers on a low income and in vulnerable circumstances. 
Ofgem should develop the same approach to incorporating vulnerability principles within suppliers' ECO programmes as it does to suppliers' delivery of energy supply. Further, the UK government should reform the regulations governing ECO delivery to make it more sensitive to meeting the needs of vulnerable consumers. This would also be in line with two of the three principles that guide the delivery of the Government's Fuel Poverty Strategy, namely 'prioritisation of the most severely fuel poor' and 'reflecting vulnerability in policy decisions' (DECC, 2015).

With respect to overall independent energy advice provision there is clearly an imbalance in England and Wales between energy market and energy efficiency advice. While some consumers are happy to access advice on-line, many households prefer to obtain it from local providers, often face to face, as outlined in Chapter 3. For the most vulnerable, home visits are necessary. Currently, straightforward energy market advice is generally available throughout the country at a local level through the Big Energy Saving Network (BESN) and Energy Advice Programme (EAP) programmes, with more specialist advice available through second tier providers (Consumer advice line and Extra Help Unit).

While BESN and EAP are not universally available and are currently only provided for part of the year, the principle of local provision is central and this is important for encouraging inclusivity. In contrast, for energy efficiency advice, this principle no longer applies in England, and this surely undermines inclusivity.

Furthermore, inclusive energy advice must recognise people's needs for other forms of support, not directly related to energy. For many people in vulnerable circumstances, these other needs will take priority over energy advice. It is therefore important that advice on a range of issues is joined up, both within and between different advice providers.

\subsection{Experiences of energy advice and how to improve them}

The citizens panel yielded detailed first hand insights into experiences of seeking help with energy related problems amongst hard to reach and vulnerable individuals. Thus it helped to address a significant gap in our understanding of how hard to reach individuals experience energy advice and what might increase engagement, improve experiences and maximise the impact of encounters where they do take place. Although the kinds of energy related problems that might affect hard to reach and vulnerable groups are fairly well documented, this study has broken new ground in generating detailed insights into how such groups seek and experience energy advice (as they understand it).

The testimonies gathered provide a clear indication that despite their mistrust of energy suppliers, they were often the first port of call when seeking to resolve an energy related problem. It was usually an affordability issue that drives this contact and the outcomes for the consumers in question were usually unsatisfactory with the problem persisting despite seeking help. Participants were very clear about where these encounters were falling short, citing disrespectful treatment that did not take account of their particular needs and circumstances. Many reported feeling exhausted and even unwell after recounting their situation repeatedly as they were transferred between departments and left frustrated over unkept promises to call them back.

Participants were also clear about how these problems might be remedied seeing face to face engagement as critical in terms of reaching more people and offering a better quality of service. They stated they would like the opportunity to be properly heard and understood rather than being 'fobbed off' or side tracked by other issues not directly relevant to their predicament. Unfortunately, energy suppliers appear to 
be moving in the opposite direction to their preferences in terms of their preferred communication method, increasingly seeking to divert customers to websites.

Participants said they had a greater level of trust in VCS organisations that offer advice and support. They may offer greater scope for face to face engagement but they were not generally the organisations that participants turned to in the first instance. Therefore, more consideration needs to be given to how vulnerable consumers can be made more aware of and guided towards advice providers which are better attuned to their needs and preferences for engagement. However, we do not wish to suggest that energy suppliers should be absolved of responsibility for better meeting the needs of vulnerable customers. They too must carefully consider how they might genuinely improve in terms of their strategy for reaching and delivering a high quality service to all customers.

\subsection{Reaching more hard to reach and vulnerable consumers}

Those present at the final stakeholder workshop (see Chapter 4) were keen to focus on the development of practical solutions to improve the reach of energy advice services and initiatives based on their own experiences in policy and practice. Some of their suggestions simply require different ways of working (e.g. working with consumers existing motivations) whilst others have more substantial resource implications (e.g. talk to everyone to avoid missing anyone) or may place additional burdens on overloaded frontline workers such as district nurses and midwives.

However, the core principles underpinning their suggestions chime with the conclusions drawn from the review in Chapter 2 as well as with some of the views and experiences of citizens panel participants in Chapter 3. All point to the need for energy advice to come from a trusted, independent source; to be delivered face to face and where possible and preferable, in the home; to focus on prevention rather than waiting for a crisis to push an individual into seeking help and to view an individual's circumstances holistically rather than trying to separate out their energy issues from broader issues of debt, financial hardship and poor quality housing, for example.

The stakeholders present also advocated an approach whereby every opportunity is taken to engage those who are hard to reach and vulnerable in a conversation about how they might be supported to improve their circumstances. This concept has been well established through the Making Every Contact Count (MECC) initiative which has gained significant traction in the health sector.

In the context of widespread support for the principle of making every contact count, it is disappointing that,- despite a significant proportion of citizens panel participants having made contact with their energy supplier, those rare opportunities for energy suppliers to learn more about their most vulnerable customers and how they might best support them were not taken. Consumers were left feeling disenchanted and not inclined to make contact again.

It seems clear that hard to reach and vulnerable energy users stand to benefit significantly from widespread adoption of the principles of MECC which all present at the stakeholder workshop agreed that these should be actively promoted and upheld in an energy advice and support context. Moreover, there is a clear mandate for this in so far as MECC is outlined in Recommendation 5 of the NICE guidelines on excess winter deaths and illness and the health risks caused by cold homes (NICE, 2015).

In the context of reaching hard to reach energy users, another lesson to emerge from the citizens panels was that working through the frontline organisations that many 
relied on when in hardship provided an effective route to engaging with those who would not traditionally engage with research. From there, careful use of the snowballing technique as advocated in a health context (Sadler et al., 2010) can expand and diversify the sample further.

The direct involvement of hard to reach groups in this research about how they access and experience energy advice and all the benefits and insights that have stemmed from that raises more fundamental questions about developing advice and support services with, rather than for, hard to reach groups. There is an extensive body of literature from the field of social exclusion that suggests that co-design of services results in effective and sustainable projects and more successful remedies for exclusion (Milbourne, 2002). Yet, in practice, there is no ready acceptance of the value of doing so. It is clear that unless such groups can find a place where their voice and their priorities are heard and accepted, then advice and support services (and not just those allied to energy) will continue to fail to meet their needs.

\subsection{Recommendations}

In addition to the specific ideas to emerge from the final stakeholder workshop (see Chapter 4 ), the project team propose the following recommendations for policy and practice:

\subsubsection{Review of current policy and practice}

- Energy companies and other service providers should take a proactive approach to making sure everybody has access to services and take positive action to address the needs of those currently missing out.

- The UK government should update the statutory provisions enshrined within the Utilities Act for addressing the needs of consumers in vulnerable circumstances. These should reflect Ofgem's current approach to understanding vulnerability and such energy market developments as the much larger number of energy companies, smart meters and decarbonisation policies.

- Ofgem should encourage all energy companies to meet the BSI inclusion standard, BSI 18477, for example by putting in place systems that reward those meeting it.

- Energy companies should develop new approaches to understanding the experiences of consumers in vulnerable circumstances and use these to improve service delivery, e.g. through commissioning independent research, supporting outreach engagement activities and working with intermediary groups in close contact with such consumers.

- Ofgem should monitor the extent to which the Energy Company Obligation (ECO) is reaching specific groups of consumers in vulnerable circumstances.

- The introduction of a state-funded energy efficiency scheme with explicit inclusion objectives to complement ECO would improve access for hard to reach households to energy efficiency measures. Irrespective of this, the UK government and Ofgem should reform the framework that governs the delivery of ECO such that it better meets the diverse needs of consumers in vulnerable circumstances.

- $\quad$ Trusted intermediaries, such as independent referral services working with front line health and other workers, can play a valuable role in making sure energy efficiency and other energy support reaches consumers in vulnerable circumstances. This is a key recommendation of the NICE NG6 guidelines. The NHS, Public Health England and relevant government departments should 
make sure that such referral services are properly funded and integrated with local health and other service provider structures.

- The UK Government should make sure that everybody has access to quality face to face local energy market and energy efficiency advice, including home visits for the most vulnerable, which complements telephone and web-based advice services. Existing energy advice programmes, such as Big Energy Saving Network and Energy Best Deal Extra have proved more effective at reaching consumers in vulnerable circumstances on a face to face basis, should put more emphasis on providing energy efficiency advice.

- Independent advice providers and accreditation bodies should establish a series of minimum standards for energy advice, building upon the NEA level 3 energy training.

\subsubsection{Review of current policy and practice}

- Work through professionals embedded in communities: such as health professionals (district nurses, midwives), housing officers, repair teams etc. They have skills in engaging with vulnerable individuals and are more likely to be trusted.

- Embed support with home energy problems into the routine management of chronic conditions and hospital discharge. Early access to support may obviate a proportion of hospital admissions and lead to improvements in chronic conditions.

- Work with agencies taking a preventative approach: including the Fire and Rescue Service (through homes safety checks) and Public Health departments which may have resource and experience to contribute.

- Work with people's existing motivations: for example, if food and/or health are of importance to households with young children then energy advice initiatives should work through these agendas.

- Be alert to energy issues that aren't perceived as such. Problems bound up with energy issues may not be perceived this way by those experiencing them. For example: respiratory problems may not be linked to a cold home and difficulties affording food may not be considered in the context of high energy bills.

- Use general financial concerns as a conversation starter: issues with debt are the most common driver of people making contact with advice agencies. Energy advice needs can often be identified through these broader conversations.

- Talk to everyone: consider 'hanging around' at key events with a wide appeal such as flu clinics and aiming to talk briefly to everyone in attendance.

- Apply the principles of Making Every Contact Count (MECC) in an energy advice context. MECC views the millions of routine engagements that various agencies have with their client base on a daily basis as an opportunity to pass on (brief) messages about healthier lifestyles. Brief messages about the importance of keeping warm at home and seeking help with obstacles to this could be embedded into routine contacts made by energy suppliers and advice providers on the same basis. 


\section{References}

ACE, CAG Consultants, Centre for Sustainable Energy and Wade, J. (2015) Closer to home.London: Citizens Advice.

Ambrose, A., McCarthy, L. and Pinder, J. (2017) Energy (in) efficiency: what tenants expect and endure in private rented housing. Eaga Charitable Trust.

Atherton, J. (2018) An Outline of Vulnerability under RIIO-2. Citizens Advice (2018), A price control for everyone. London: Citizens Advice.

Baker, K., Mould, R., Stewart, F., Restrick, S., Melone, H. and Atterson, B. (2019) Never try and face the journey alone: exploring the face-to-face advocacy needs of fuel poor householders in the United Kingdom. Energy Research and Social Science, 51, pp. 210-219.

Baker, W. (2001) Competitive energy markets and low income consumers. Centre for Sustainable Energy.

Baker, W., White, V. and Preston, I. (2008) Quantifying rural fuel poverty. Eaga Charitable Trust.

BEIS (2018a) Energy Company Obligation: ECO3, 2018 - 2022: the government response to the ECO3 2018-2022 consultation. London: BEIS.

BEIS (2018b) Domestic rented sector minimum level of energy efficiency. Government Response to the consultation on proposals to amend The Energy Efficiency (Private Rented Property) (England and Wales) Regulations 2015. BEIS: London.

BEIS (2019) Energy Company Obligation: ECO3, 2018-22 Flexible eligibility guidance. Guidance for local authorities on engaging with energy suppliers to identify households that would benefit from energy efficiency improvements. London: BEIS.

BEIS Committee (2019) Energy efficiency: building towards net zero. Twenty-First Report of Session 2017-19. House of Commons.

Boardman, B. and Darby, S. (2000) Effective advice - energy efficiency and the disadvantaged. Oxford: Environmental Change Institute, University of Oxford.

Boddy, C.R. (2011) Hanging around with people. Ethnography in marketing research and intelligence gathering. The Marketing Review, 11(2), pp. 151-163.

Bonfield, P. (2016) Each home counts - an independent review of consumer advice, protection, standards and enforcement for energy efficiency and renewable energy. London: BEIS and DCLG. 
Brackertz, N. and Meredyth, D. (2008) Social inclusion of the hard to reach - community consultation and the hard to reach: local government, social profiling and civic infrastructure, quoted in Cardiff Council, (2009). A literature review of engaging hard to reach/hear groups. Cardiff: Cardiff Council.

Buzar, S. (2007) Energy Poverty in Eastern Europe: Hidden Geographies of Deprivation. Ashgate.

BSI (2010) Fair, flexible services for all - a summary of the British Standard for inclusive service provision - identifying and responding to consumer vulnerability (BS 18477: 2010). BSI.

Cardiff Council (2009) A literature review of engaging hard to reach/hear groups, Research report for the Local service board scrutiny panel. Cardiff: Cardiff Council.

Centre for Competition Policy (2018) Fairness in retail energy markets? Centre for Competition Policy, University of East Anglia.

Citizens Advice (2017) Energy Advice Strategy, internal document.

Citizens Advice (2018a) A price control for everyone; a collection of individually authored essays on how RIIO-2 can deliver improved support for people in vulnerable circumstances. London: Citizens Advice.

Citizens Advice (2018b) Warm homes, affordable fuel and healthy people - how local Citizens Advice can help. London: Citizens Advice.

Citizens Advice (2019) evidence submitted to BEIS inquiry into energy efficiency, in BEIS Committee (2019), Energy efficiency: building towards net zero. Twenty-First Report of Session 2017-19. House of Commons.

Commission for Customers in Vulnerable Circumstances (2019) The commission for customers in vulnerable circumstances. Energy UK.

Committee on Fuel Poverty (2018) Committee on Fuel Poverty - third annual report. London: BEIS.

Crisp, T. and Kruja, K. (2019) Future for all. Making a future retail energy market work for all. London: Citizens Advice.

Emden, J., Murphy, L. and Lloyd, H. (2018) Beyond ECO - the future of fuel poverty support. IPPR.

End Fuel Poverty Coalition (EFPC) and the Economic and Social Research Council (2018) ESRC/End Fuel Poverty Coalition seminar on health impact of cold homes and fuel poverty, 6 February 2018.

Energy UK (2016a) The Energy UK safety net - protecting vulnerable customers from disconnection. Energy UK.

Energy UK (2016b) Prepayment meter principles. Energy UK.

Fahmy, E. (2011) The definition and measurement of fuel poverty: a briefing paper for Consumer Focus submission to the Hills fuel poverty review. Consumer Focus.

FPS (2013) Code of Practice for Domestic Supplies of Heating Oil. Federation of Petroleum Suppliers. 
Freimuth, V.S. and Mettger W.M. (1990) Is there a hard to reach audience? Public Health Reports, May - June, 105 (3).

Gousy, H. (2014) Can't Complain. London: Shelter.

Gordon, D., Mack, J., Lansley, S., Main, G., Nandy, S., Patsios, D. and Pomati, M. The Impoverishment of the UK. PSE UK first results: Living Standards. PSE UK.

Hills, J. (2012) Getting the measure of fuel poverty - final report of the fuel poverty review. Centre for analysis of social exclusion.

IRISS (2011) Effectively engaging and involving seldom-heard groups. Institute for Research and Innovation in Social Services.

Liquid Gas (2017) Liquid gas UK customer charter. Liquid Gas.

MHCLG (2019) English Housing Survey - headline report 2017-18. Ministry of Housing, Communities and Local Government.

Middlemiss, L. and Gillard, R. (2015) Fuel poverty from the bottom-up: characterising household energy vulnerability through the lived experience of the fuel poor. Energy Research \& Social Science, 6 March 2015, pp.146-154.

Milbourne, L. (2002) Unspoken Exclusion: Experiences of continued marginalisation from education among 'hard to reach' groups of adults and children in the UK. British Journal of Sociology of Education, 23(2), pp. 287-305.

Mould, R. and Baker, K. (2017) Documenting fuel poverty from the householders' perspective, Energy Research \& Social Science, 31, Sept 2017, pp. 21-31.

National Audit Office (2016) Green Deal and Energy Company Obligation - HC 607 session 2015-16, 14 April 2016. National Audit Office.

NEA (2019) Focus, 24, Spring 2019, p.11.

NEA (2019) evidence submitted to BEIS inquiry into energy efficiency, in BEIS Committee (2019), Energy efficiency: building towards net zero Twenty-First Report of Session 2017-19. House of Commons.

NICE (2015) Excess winter deaths and illness and the health risks associated with cold homes, NICE (National Institute of health and Care Excellence) guideline, NG6. NICE.

Ofgem (2013) Consumer vulnerability strategy. Ofgem.

Ofgem (2019) Draft consumer vulnerability strategy 2025. Ofgem.

Pfaelzer, J. (2010) Hanging out: A Research Methodology. Legacy, 27(1).

Roberts, S. (2018) Making 'no one left behind' meaningful in our future energy system, in Citizens Advice (2018), A price control for everyone. London: Citizens Advice.

Ruse, J. and Garlick, K. (2018) Under one roof: health and housing sectors tackling fuel poverty and cold-related ill health together. National Energy Action.

Ruse, J. and Burroughs, J. (2016) Get warm soon? National Energy Action. 
Sadler, G.R., Lee, H.C., Sueng-Hwan, Lim R. and Fullerton, J. (2010) Recruitment of hardto-reach population subgroups via adaptations of the snowball sampling strategy. Nursing and Health Sciences, 12, pp. 369-374.

Scottish Government (2017) A review of the definition of fuel poverty in Scotland - a review of recent evidence. Scottish Government.

Scottish Government (2018) Consultation Analysis: Energy Efficient Scotland: making our homes and buildings warmer, greener and more efficient. Analysis of responses to the public consultation exercise. Scottish Government.

Snell, C., Bevan, M., Gillard, R., Wade, J. and Greer, K. (2018) Policy pathways to justice in energy efficiency. UK Energy Research Centre.

Stearn, J. (2016) Consumer vulnerability is market failure, in Hamilton, K., Dunnet, S. and Piacentini, M. (2016) Consumer vulnerability- conditions, contexts and characteristics. Routledge.

Sustainability First (2018) Project Inspire, Sustainability First.

Thompson, H., Bouzarski, S. and Snell, C. (2017) Rethinking the measurement of energy poverty in Europe: a critical analysis of indicators and data. Indoor \& Built Environment, 26(7), pp. 879-901.

Thomas, S. (ed) (2008) Poor Choices: The limits of competitive markets in the provision of essential services to low income consumers. London: Energywatch.

UK Government (2015) Cutting the cost of keeping warm - a fuel poverty strategy for England. UK Government.

UK Government (2017) The clean growth strategy - leading the way to a low carbon future. UK Government.

Welsh Government (2008) The Welsh Housing Quality Standard. Welsh Government.

Williams, R. and Whyte, S. (2018) Energy Best Deal evaluation. London: Citizens Advice. 


\section{Sheffield Hallam University}

Reaching the 'Hardest to Reach' with energy advice: final report

AMBROSE, Aimee <http://orcid.org/0000-0002-5898-6314>, BAKER, William, BATTY, Elaine <http://orcid.org/0000-0001-7524-3515> and HAWKINS, Anna

Available from the Sheffield Hallam University Research Archive (SHURA) at:

http://shura.shu.ac.uk/25246/

\section{Copyright and re-use policy}

Please visit http://shura.shu.ac.uk/25246/ and http://shura.shu.ac.uk/information.html for further details about copyright and re-use permissions. 